\title{
Regulated Cationic Channel Function in Xenopus Oocytes Expressing Drosophila Big Brain
}

\author{
Gina M. Yanochko ${ }^{1}$ and Andrea J. Yool ${ }^{1,2}$ \\ ${ }^{1}$ Program in Pharmacology and Toxicology and ${ }^{2}$ Departments of Pharmacology and Physiology, College of Medicine, \\ University of Arizona, Tucson, Arizona 85724-5051
}

\begin{abstract}
Big brain (bib) is a neurogenic gene that when mutated causes defects in cell fate determination during Drosophila neurogenesis through an unknown mechanism. The protein Big Brain (BIB) has sequence identity with the major intrinsic protein family that includes the water- and ion-conducting aquaporin channels. We show here that BIB expressed heterologously in Xenopus oocytes provides a voltage-insensitive, nonselective cation channel function with permeability to $\mathrm{K}^{+}>\mathrm{Na}^{+} \gg$ tetraethylammonium. The conductance, activated in response to endogenous signaling pathways in BIB-expressing oocytes, is decreased after treatment with $20 \mu \mathrm{M}$ insulin and is enhanced with $10 \mu \mathrm{M}$ lavendustin A, a tyrosine kinase inhibitor. Western blot analysis confirms that BIB is tyrosine-phosphorylated.
\end{abstract}

Neurogenic genes separate neural precursors (neuroblasts) and epidermal precursors (epidermoblasts) from the Drosophila neuroectoderm through a process termed lateral inhibition (Greenspan, 1992). Loss-of-function mutations in these genes cause central and peripheral nervous system overgrowth (Lehmann et al., 1983; Brand and Campos-Ortega, 1988; Han et al., 1998a; Artavanis-Tsakonas et al., 1999). The neurogenic phenotype induced by loss-of-function mutations of the gene big brain (bib) is less severe than that for other neurogenic genes (Lehmann et al., 1983; Goriely et al., 1991; Rao et al., 1992). The molecular contributions of the neurogenic genes Notch (a transmembrane receptor) and Delta (a transmembrane ligand for Notch) have been identified (Fehon et al., 1990; Artavanis-Tsakonas et al., 1995). Suppressor of Hairless, and the Enhancer of Split gene complex contribute to a signaling pathway, regulating the signal from Notch to the nucleus (Delidakis and Artavanis-Tsakonas, 1992; Fortini and Artavanis-Tsakonas, 1994; Bailey and Posakony, 1995; Kimble and Simpson, 1997; Lai et al., 2000). Although the Big Brain protein (BIB) is located on the plasma membrane and can interact functionally with Notch and Delta, its

Received May 29, 2001; revised Jan. 7, 2002; accepted Jan. 10, 2002.

This work was supported by National Institutes of Health (NIH) Grant RO1 GM 59986 (A.J.Y.), NIH Training Grant T32 NS-07363, and a University of Arizona dean's fellowship (G.M.Y.). We thank A. Marble for technical assistance, Dr. J. G. Richman for assistance with mutagenesis strategies, Dr. R. R. Vaillancourt for assistance with epitope tagging and Western blotting strategies, Dr. T. L. Anthony for assistance with confocal imaging, Dr. J. W. Regan for use of an oocyte-imaging system, and Dr. D. Doherty for helpful discussions.

Correspondence should be addressed to Dr. Andrea J. Yool, Department of Physiology, University of Arizona, P.O. Box 245051, Tucson, AZ 85724-5051. E-mail: ayool@u.arizona.edu.

Dr. Yanochko's present address: Molecular and Cell Biology Laboratory, The Salk Institute for Biological Studies, 10010 North Torrey Pines Road, La Jolla, CA 92037-1099.

Copyright (C) 2002 Society for Neuroscience $\quad 0270-6474 / 02 / 222530-11 \$ 15.00 / 0$
Both tyrosine phosphorylation and the potentiating effect of lavendustin $\mathrm{A}$ are removed by partial deletion of the $\mathrm{C}$ terminus (amino acids 317-700). Current activation is not observed in control oocytes or in oocytes expressing a nonfunctional mutant (BIB E71N) that appears to be expressed on the plasma membrane by confocal microscopy and Western blotting. These results indicate that BIB can participate in tyrosine kinase-regulated transmembrane signaling and may suggest a role for membrane depolarization in the neurogenic function of $\mathrm{BIB}$ in early development.

Key words: major intrinsic protein; Xenopus oocyte; tyrosine kinase; voltage clamp; neurogenic; aquaporin

mechanism of action within the established signaling pathway for Notch is unclear (de la Concha et al., 1988; Doherty et al., 1997). Rao et al. (1990) suggested that BIB directly mediates intercellular communication in the neuroectoderm.

The proposed membrane topology of BIB predicts six transmembrane domains with intracellular $\mathrm{N}$ and $\mathrm{C}$ termini (Rao et al., 1990). This structure is similar to members of the major intrinsic protein (MIP) family that includes aquaporins, mammalian channels for water as well as other solutes including ions (Ehring et al., 1990; Reizer et al., 1993; Yool et al., 1996; Tsukaguchi et al., 1998; Yasui et al., 1999). BIB has high amino acid sequence identity with aquaporins (AQPs): $38 \%$ overall identity with AQP0 (Rao et al., 1990), and 32\% overall identity with AQP4 (Adams et al., 1992). BIB has a large C-terminal tail domain (427 amino acids) that contains many putative consensus sites for kinase-mediated modulation (Burris et al., 1998; this study).

Despite the established involvement of BIB in developmental pathways and its sequence identity to aquaporins, its function has previously remained unknown. We show here that BIB expressed in Xenopus oocytes confers new function of a regulated ion channel. Water and ionic permeability were investigated with osmotically induced swelling assays and twoelectrode voltage-clamp recordings. Our results demonstrate that BIB is not appreciably permeant to osmotic water flux. Several lines of evidence support the idea that BIB does function as a kinase-regulated nonselective cation channel. Given the importance of tyrosine kinases in growth factormediated control of nervous system development (Pimentel et al., 1996; Skeath, 1998; Udolph et al., 1998; Chen et al., 1999), we suggest that the observed properties of BIB are consistent with a role in transmembrane voltage signaling as an essential early step in neurogenesis. 


\section{MATERIALS AND METHODS}

Oocyte preparation and injection. Stage V-VI oocytes from adult female Xenopus laevis were obtained and defolliculated as described by Anthony et al. (2000). Prepared oocytes were injected with $50 \mathrm{nl}$ of sterile water (control oocytes) or $50 \mathrm{nl}$ of sterile water containing bib cRNA $(0.4 \mathrm{ng} / \mathrm{nl}$ unless otherwise indicated) and were incubated for $2-5 \mathrm{~d}$ at $18^{\circ} \mathrm{C}$ in ND96 culture medium $\left(96 \mathrm{~mm} \mathrm{NaCl}, 2 \mathrm{~mm} \mathrm{KCl}, 1.8 \mathrm{~mm} \mathrm{CaCl}_{2}, 1 \mathrm{~mm}\right.$ $\mathrm{MgCl}_{2}, 5 \mathrm{~mm}$ HEPES, $2.5 \mathrm{~mm}$ pyruvic acid, $100 \mathrm{U} / \mathrm{ml}$ penicillin, and 100 $\mu \mathrm{g} / \mathrm{ml}$ streptomycin, $\mathrm{pH}$ 7.6) to allow protein expression before recording.

Electrophysiology. Two-electrode voltage clamp was used to investigate the macroscopic ion channel properties of oocytes expressing BIB. Recordings were performed at room temperature with electrodes $(0.5-3$ $\mathrm{M} \Omega$ ) filled with $3 \mathrm{~m} \mathrm{KCl}$. Data were recorded with a GeneClamp 500 (Axon Instruments, Foster City, CA), filtered at $2 \mathrm{kHz}$, digitized at $50-2000 \mu \mathrm{sec}$, and analyzed with pClamp software (Axon Instruments). Recording salines for two-electrode voltage clamp contained (in $\mathrm{mM}$ ): $100 \mathrm{NaCl}, 2 \mathrm{KCl}, 4.5 \mathrm{MgCl}_{2}$, and $5 \mathrm{HEPES}, \mathrm{pH}$ 7.3. Reversal potentials were obtained from a polynomial fit (second order) of the currentvoltage relationship for each oocyte and used to calculate relative ionic permeability. Relative ionic permeability was calculated from the reversal potential (Er) with a simplified equation for bi-ionic conditions (Hille, 1992): $P_{\mathrm{X}} / P_{\mathrm{K}}=\left([\mathrm{K}]_{\mathrm{i}} /[X]_{\mathrm{o}}\right) \exp ^{(\mathrm{Er} / 58)}$, where $P_{\mathrm{X}} / P_{\mathrm{K}}$ is the relative permeability to the test ion $X^{+}$, Er is the reversal potential, $[X]_{\mathrm{o}}$ is the concentration of the test ion in the extracellular saline, and $[\mathrm{K}]_{\mathrm{i}}$ is the calculated internal $\mathrm{K}^{+}$concentration. The internal $\mathrm{K}^{+}$concentration was estimated for each oocyte from the Nernst equation by the reversal potential in bath saline with $100 \mathrm{mM} \mathrm{K}^{+}$(internal $\mathrm{K}^{+}$ranged from 110-133 mm). 1-(5-Isoquinolinesulfonyl)-2-methylpiperazine (H7), insulin, lavendustin A, and staurosporine were purchased from Sigma (St. Louis, MO).

Molecular techniques. Drosophila big brain cDNA was generously provided by Dr. Lily Jan (Rao et al., 1990). We subcloned the coding region of bib into the plasmid $\mathrm{pX} \beta \mathrm{Gev}$, a Xenopus expression vector. For subcloning, the coding region of bib was amplified by PCR with highfidelity Pyrococcus woesei polymerase (Roche Molecular Biochemicals, Indianapolis, IN) using sense and antisense primers that introduced BglII (Roche Molecular Biochemicals) restriction sites (underlined) into the $5^{\prime}$ - and $3^{\prime}$-untranslated regions of the bib cDNA: sense, 5'-AAC AAA TCG AGA TCT GAG TCC GAC ATG-3' (bp 277-303); and antisense, 5'-ACC CCA GAT CTG CCG CTT TCA GTT GGG-3' (bp 2421-2395).

To visualize BIB channels by immunofluorescence microscopy and Western blotting, an epitope tag consisting of nine amino acids (YPYDV PDYA) from the influenza hemagglutinin (HA) protein was inserted in the $\mathrm{N}$ terminus of BIB. Incorporation of the HA peptide sequence required two rounds of PCR. The sense primer for the first reaction contained the last seven codons of the HA epitope (underlined) followed by a region of overlap with the $b i b$ sequence: $5^{\prime}$-TAC GAC GTG CCG GAC TAC GCT GCC GAC GAA AGT CTG-3' (bp 304-318). The antisense primer was the same as used for bib subcloning (above). The sense primer for the second PCR contained the rest of the HA sequence (underlined), the start codon (italics), and a BglII restriction site (bold): 5'-TCG AGA TCT GAG TCC GAC $A T G$ TAC CCG TAC GAC GTG CCG GAC-3' with the same antisense primer as above. The entire coding sequences of all constructs were sequenced to verify that no inadvertent mutations were introduced.

Site-directed mutagenesis was performed with a QuickChange sitedirected mutagenesis kit (Stratagene, La Jolla, CA). Glu ${ }^{71}$ was mutated to Asn (E71N), using the following primer combinations (mutated base pairs underlined): sense, 5'-GGA GAT CCA TCA TCA GCA ACT GTC TGG CCT CC-3' (bp 494-525); and antisense, 5'-GGA GGC CAG ACA GTT GCT GAT GAT GGA TCT CC-3' (bp 525-494). The BIB truncation mutation $(\Delta 317)$ has a partial deletion of the $\mathrm{C}$-terminal domain from amino acid 317 to the end. The $\Delta 317$ mutant was synthesized by PCR. The sense primer sequence spanned the start codon (italics) and introduced a $\mathrm{Bgl} I I$ site (underlined; mutated residues are in bold) to facilitate subcloning: 5'-AACAAATCGAGATCTGAGTCCGACATG-3' (bp 277303). The antisense primer introduced a stop codon at position 317 (italics) and incorporated a $\mathrm{BglII}$ restriction site (underlined; mutated residues are in bold) for subsequent subcloning into the $\mathrm{p} X \beta \mathrm{G}$ expression vector: 5'-GGTGCAGATCTACTGCTGTCACTTGTTGGGCTTCTC-3' (bp 1266-1231).

Plasmid DNA was linearized with SpeI in the polylinker region and used to transcribe RNA in vitro with T3 RNA polymerase. Enzymes were purchased from Roche Molecular Biochemicals.

Swelling assay. Analysis of water permeability was performed as described by Rivers et al. (1997). Oocytes were placed in 50\% hypotonic saline (1:1 dilution of ND96 with deionized water), and swelling was monitored by video microscopy. Images were taken every $15 \mathrm{sec}$ with a CCD camera (Cohu Inc., San Diego, CA) and analyzed with IPLab spectrum software (Scanalytics Inc., Fairfax, VA). The relative volume was calculated from the two-dimensional area of the oocyte as a function of time of exposure to hypotonic saline and was used to determine the net osmotic water permeability.

Cellular fractionation. Two to $3 \mathrm{~d}$ after RNA injection, oocyte fractions enriched in plasma membranes were isolated by a method adapted from that of Geering et al. (1989). Briefly, 15 oocytes per group were isolated in $1 \mathrm{ml}$ of lysis buffer (1\% Triton X-100, $10 \mathrm{~mm}$ Tris- $\mathrm{HCl}, 50 \mathrm{~mm} \mathrm{NaCl}$, $50 \mathrm{~mm} \mathrm{NaF}$, and $1 \%$ aprotinin) supplemented with leupeptin $(10 \mu \mathrm{g} / \mathrm{ml})$, pepstatin A $(10 \mu \mathrm{g} / \mathrm{ml})$, PMSF $(10 \mathrm{~mm})$, and sodium orthovanadate $(2$ $\mathrm{mm}$ ) and lysed by trituration. Oocyte lysates were incubated on ice $\sim 10$ min followed by centrifugation $(400 \times g)$ for $10 \mathrm{~min}$ at $4^{\circ} \mathrm{C}$ to remove yolk granules. The supernatant was removed to a clean tube, and samples were centrifuged again $(400 \times g)$ for $10 \mathrm{~min}$ at $4^{\circ} \mathrm{C}$, yielding a yolkdepleted supernatant. A pellet enriched in plasma membrane fractions was obtained after centrifugation of the supernatant $(12,000 \times \mathrm{g}, 20 \mathrm{~min}$, $\left.4^{\circ} \mathrm{C}\right)$. Pellets were resuspended in $50 \mu \mathrm{l}$ of lysis buffer and used for immunoprecipitation or were resuspended in $25 \mu \mathrm{l}$ of Laemmli buffer (10\% glycerol, $50 \mathrm{~mm}$ Tris $\mathrm{HCl}, 2 \%$ SDS, $5 \% \beta$-mercaptoethanol, and $0.02 \%$ bromophenol blue) and used for Western blotting. Leupeptin, pepstatin A, PMSF, and sodium orthovanadate were purchased from Sigma.

Immunoprecipitation and Western blotting. Equivalent amounts of protein $(20-30 \mu \mathrm{g})$ were used for immunoprecipitation. Sample volumes were increased to $\sim 1 \mathrm{ml}$ with lysis buffer followed by addition of the primary antibody $(0.5 \mu \mathrm{g}$ of rat anti-HA high-affinity clone $3 \mathrm{~F} 10$, Roche Molecular Biochemicals; or $0.5 \mu \mathrm{g}$ of PY11120 antibody, Transduction Laboratories, Lexington, KY) and incubated overnight at $4{ }^{\circ} \mathrm{C}$ with rotation. Rabbit anti-rat IgG $(0.5 \mu \mathrm{g})$ was added to samples immunoprecipitated with rat HA antibody and incubated for $1 \mathrm{hr}$. Ten microliters of a 1:1 slurry of protein A-Sepharose (Sigma) were added to all samples and then rotated for $1 \mathrm{hr}$ at $4^{\circ} \mathrm{C}$. Proteins were precipitated by brief centrifugation steps $(12,000 \times g, 1 \mathrm{~min})$ and washed twice with lysis buffer and once in buffer containing $0.1 \%$ Triton X-100. Laemmli buffer was added to each sample (10\% glycerol, $50 \mathrm{~mm}$ Tris-HCl, $2 \%$ SDS, $5 \%$ $\beta$-mercaptoethanol, and $0.02 \%$ bromophenol blue). Proteins resolved by $8 \%$ SDS-PAGE were transferred to nitrocellulose (Bio-Rad, Hercules, $\mathrm{CA})$ in transfer buffer (10\% methanol and $10 \mathrm{~mm} 3$-(cyclohexylamino)1-propanesulfonic acid; Sigma) for $1 \mathrm{hr}$ at $1 \mathrm{~A}$. Nonspecific binding sites were blocked with $1.5 \%(\mathrm{w} / \mathrm{v})$ evaporated milk in TBST $(154 \mathrm{mM} \mathrm{NaCl}$, $10 \mathrm{~mm}$ Tris base, and $0.02 \%$ Tween 20 ) and $0.01 \%$ thimerosal (for HA antibody) or with $3 \%(\mathrm{w} / \mathrm{v})$ bovine serum albumin in TBST and $0.01 \%$ thimerosal (for phosphotyrosine and phosphoserine antibodies). After blocking, blots were exposed to rat anti-HA antibody (clone 3F10, 50 $\mathrm{ng} / \mathrm{ml}$ ), mouse anti-phosphoserine antibody (clone PSR-45, Sigma; 1 $\mu \mathrm{g} / \mathrm{ml}$ ) or mouse anti-phosphotyrosine antibody (PY11120, $1 \mu \mathrm{g} / \mathrm{ml}$ ) for $1 \mathrm{hr}$ at room temperature or overnight at $4^{\circ} \mathrm{C}$, followed by three $15 \mathrm{~min}$ washes in TBST at room temperature. To visualize proteins recognized by the primary antibodies, blots were incubated with goat anti-rat or anti-mouse HRP conjugates $(0.3 \mu \mathrm{g} / \mathrm{ml}$; Zymed, San Francisco, CA) for $1 \mathrm{hr}$ at room temperature, followed by three $15 \mathrm{~min}$ washes at room temperature. Bands were visualized by enhanced chemiluminescence (Pierce, Rockford, IL).

Immunofluorescence labeling of intact oocytes. Intact oocytes on day 2 or 3 after cRNA injection were fixed in $4 \%$ paraformaldehyde for 2-3 hr at $4^{\circ} \mathrm{C}$, followed by brief rinses in $30 \mathrm{~mm}$ SSC $(300 \mathrm{~mm}$ sodium chloride and $20 \mathrm{~mm}$ sodium citrate) and $100 \mathrm{~mm}$ glycine. Oocytes were permeabilized for $1 \mathrm{hr}$ in $30 \mathrm{~mm}$ SSC containing $0.1 \%$ Triton X-100, followed by overnight incubation with a rat anti-HA antibody $(0.5 \mu \mathrm{g} / \mathrm{ml}$; clone 3F10, Roche Molecular Biochemicals) diluted in antibody dilution buffer (30 mu SSC, $2 \%$ goat serum, $1 \%$ bovine serum albumin, $0.05 \%$ Triton $\mathrm{X}-100$, and $0.02 \%$ sodium azide). Oocytes were washed in antibody wash buffer (30 mm SSC and $0.05 \%$ Triton X-100) for $1 \mathrm{hr}$, followed by incubation for $1 \mathrm{hr}$ with FITC-conjugated goat anti-rat antibody (1 $\mu \mathrm{g} / \mathrm{ml}$ ) diluted in antibody dilution buffer. Oocytes were rinsed with antibody wash buffer for $1 \mathrm{hr}$ and imaged with a $10 \times$ objective (pinhole size 100) on a Leica (Nussloch, Germany) TCS-4D laser scanning confocal microscope. 


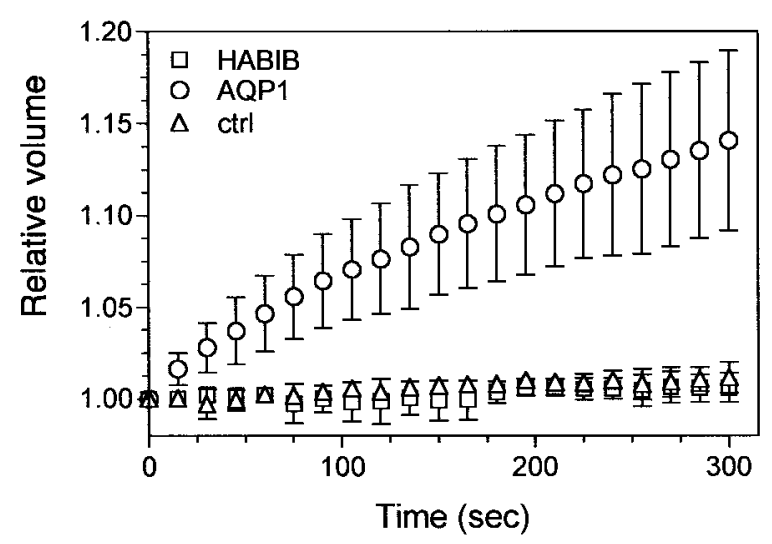

Figure 1. BIB expression does not confer osmotically induced swelling in Xenopus oocytes. A, Osmotic water permeability was analyzed with a swelling assay (see Materials and Methods). Oocytes expressing human aquaporin-1 (circles; $n=5)$ or HABIB (squares; $n=4)$ and control (ctrl) oocytes (triangles; $n=4$ ) were exposed to hypotonic saline at time 0 , and the relative volume change with time was measured from the videoimaged cross-sectional area. Data are mean \pm SD from a representative experiment; $n=4$ or 5 oocytes per group.

All data summaries are reported as mean $\pm \mathrm{SD}$. Statistical significance was tested with a two-tailed Student's $t$ test; $p<0.05$ was used to determine significance.

\section{RESULTS}

BIB has amino acid sequence identity with aquaporins of the MIP family (Rao et al., 1990; Adams et al., 1992; Reizer et al., 1993). Therefore, we compared the water permeability of oocytes expressing HABIB with that of oocytes expressing AQP1, a well characterized water channel (Preston et al., 1992). Figure 1 shows the results from a representative experiment that was replicated in four batches of oocytes. By $5 \mathrm{~min}$ of exposure to $50 \%$ hypotonic saline, the relative volume of oocytes expressing AQP1 increased by an average of $12.5 \%$, yielding a calculated water permeability factor $\left(P_{\mathrm{f}}\right)$ value of $26 \pm 13 \mu \mathrm{m} / \mathrm{sec}(n=5)$. In contrast, the relative volume of oocytes expressing HABIB did not increase and remained similar to control oocytes during $5 \mathrm{~min}$ in hypotonic saline or longer; $P_{\mathrm{f}}$ values were $-1 \pm 5 \mu \mathrm{m} / \mathrm{sec}(n=$ $4)$, and $2 \pm 1 \mu \mathrm{m} / \mathrm{sec}(n=4)$, respectively. These data show that despite the sequence similarity between BIB and aquaporins, $\mathrm{BIB}$ is not a water channel under the conditions tested.

Several members of the MIP family have ion channel activity (Ehring et al., 1990; Weaver et al., 1994; Yool et al., 1996; Yasui et al., 1999; Anthony et al., 2000). Two-electrode voltage clamp was used to test for ionic conductance properties of BIB channels. Figure 2 shows the activation of channels in BIB-expressing oocytes measured as an increase in whole-cell conductance. We initially tested BIB-expressing oocytes by placing them into recording saline, immediately inserting recording electrodes, and assessing the response (if any) to a series of voltage steps from +60 to $-90 \mathrm{mV}$ from a holding potential of $-40 \mathrm{mV}$. BIBexpressing and control oocytes consistently showed no appreciable conductance immediately after electrode insertion (Fig. $2 A$, $a, d)$. However, we noticed during sustained recordings that BIBexpressing oocytes showed an increase in current beginning $\sim 5$ min after the initial electrode insertion; this response was absent from control oocytes. The current-voltage relationship of the activated current was linear ( +60 to $-90 \mathrm{mV}$; Fig. $2 A, e$ ), in contrast to a lack of response in control oocytes (Fig. $2 A, b$ ). The net responses (Fig. $2 A, c, f$ ) were obtained by subtracting the set of initial traces from the final.

Figure $2 B$ shows the time-dependent spontaneous activation of channels triggered by electrode penetrations of BIB-expressing oocytes. The current response was monitored with a protocol to measure the voltage dependence of activation, briefly, repeated steps to $+40 \mathrm{mV}$ ( $800 \mathrm{msec}$ duration) every $5 \mathrm{sec}$ from a holding potential of $-40 \mathrm{mV}$ (Anthony et al., 2000). In oocytes expressing $\mathrm{BIB}$ channels, the current began to activate $\sim 5$ min after electrode insertion and reached a plateau at $\sim 20-30$ min after electrode insertion (Fig. 2B). In contrast, control oocytes did not display any comparable increase in current over equal durations or longer. The rate of activation (Fig. $2 C$ ) was calculated from a linear fit of current plotted as a function of time, for the interval between 5 and $13 \mathrm{~min}$. Control oocytes had a significantly lower rate of change in membrane conductance $(8 \pm 12 \mathrm{nA} / \mathrm{min} ; p<$ $0.05)$ than did BIB-expressing oocytes $(30 \pm 25 \mathrm{nA} / \mathrm{min})$. Spontaneous activation in BIB-expressing oocytes was not affected by holding potential or voltage steps. Tests of different voltage steps $(-40,0,+60$, and $+80 \mathrm{mV})$ indicated no apparent effect of voltage on the rate or magnitude of channel activation (data not shown). Simply placing oocytes into recording saline for equivalent periods did not elicit a current response, indicating that spontaneous activation was initiated by the pricking effect of electrode insertion. Possible activation mechanisms are addressed further in Figure 3.

Averaged current-voltage relationships measured for control and BIB-expressing oocytes are shown in Figure 2D. The linear relationship shows a voltage-independent conductance, with a reversal potential consistent with a nonselective cationic conductance (Fig. 4). The box plot (Fig. 2E) summarizes the net conductance at $30 \mathrm{~min}$ after electrode insertion for control and BIB-expressing oocytes, calculated from linear fits of the net current-voltage relationship for each oocyte. Control oocytes had a mean net conductance of $1 \pm 4 \mathrm{nA} / \mathrm{mV}(n=10)$. Wild-type BIB-expressing oocytes had a mean net conductance of $17 \pm 11$ $\mathrm{nA} / \mathrm{mV}(p<0.0001 ; n=19)$ that was significantly greater than that of control oocytes.

To visualize BIB channels with immunofluorescence and Western blots, we inserted an HA epitope (for details, see Materials and Methods) into the amino terminus of BIB (HABIB) and tested the effect of epitope insertion on BIB channel properties. Representative current traces shown in Figure $2 A$ show that the effects of BIB and HABIB expression are indistinguishable in general properties. HABIB-expressing oocytes (Fig. 2C) were not significantly different from oocytes expressing wild-type $\mathrm{BIB}$ in the rate of activation $(30 \pm 25 \mathrm{nA} / \mathrm{min} ; n=22$; and $42 \pm$ $42 \mathrm{nA} / \mathrm{min} ; n=19$, respectively) or in net conductance (Fig. $2 E$ ). These results showed that insertion of the HA epitope did not affect the activation of ionic conductance or current-voltage relationship of the response.

Because neither voltage nor exposure to recording saline induced spontaneous activities, we hypothesized that insertion of recording electrodes was activating a signaling pathway. A simple leak current was ruled out by the observation that control oocytes had no response (Fig. 2). Oocytes are known to be induced to progress through the cell cycle artificially by pricking (Wolf, 1974; Kubota et al., 1987; Wangh, 1989) or normally by fertilization; both processes involve kinase-mediated pathways including tyrosine phosphorylation and dephosphorylation (Sato et al., 1998; Glahn et al., 1999; Sato et al., 1999). MIP family channels are targets of kinase-mediated cell signaling (Ehring et al., 1991; 

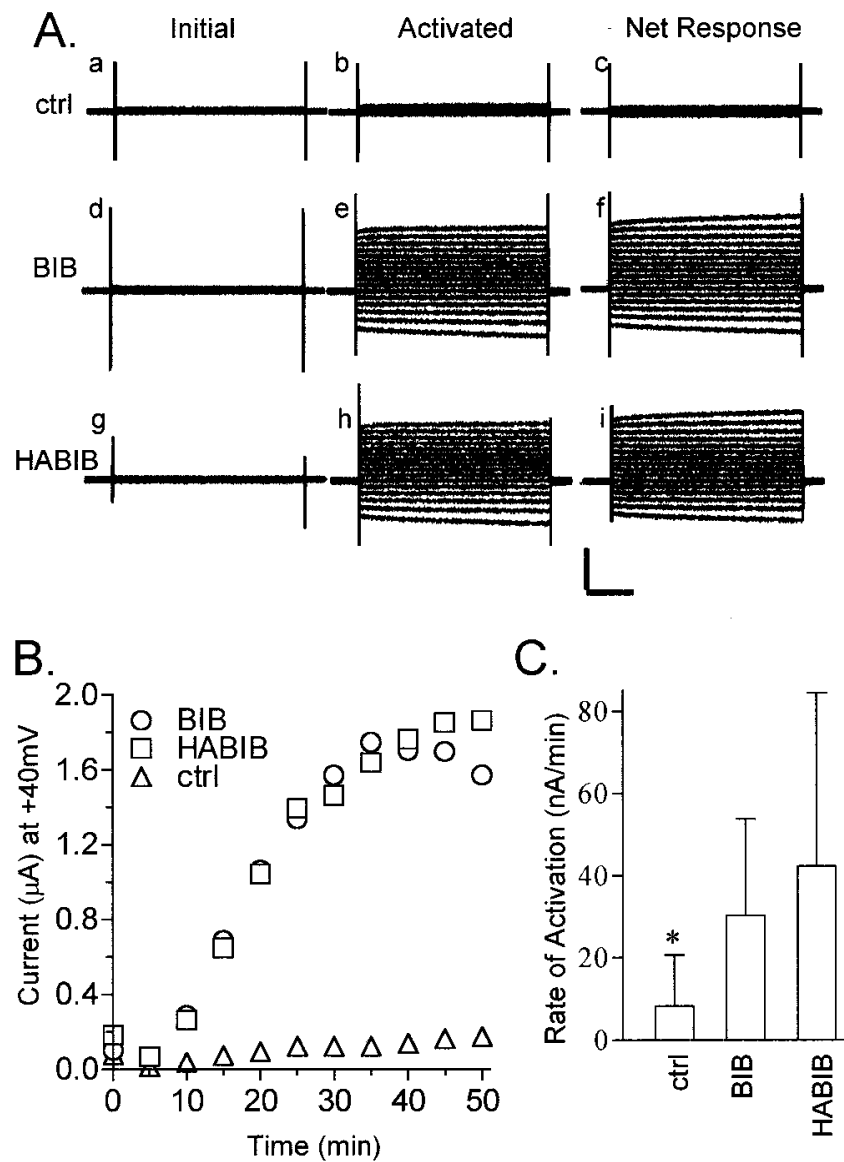

C.
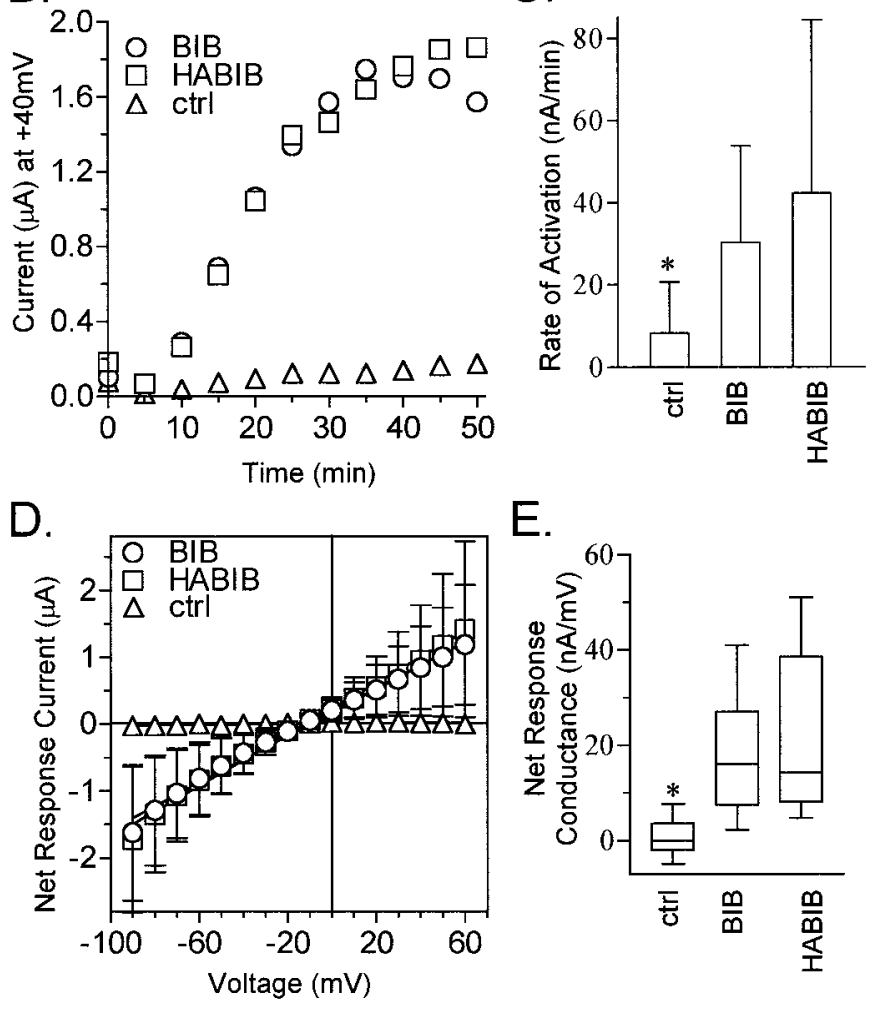

E.

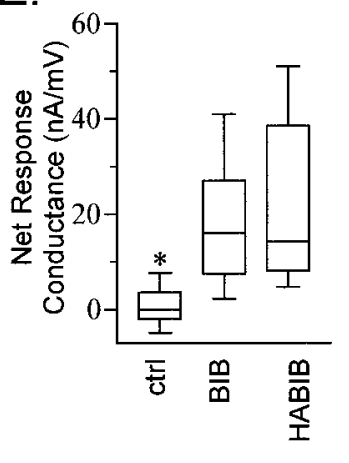

Figure 2. Ion channel activity in BIB-expressing oocytes. $A$, Representative traces from control $(c t r l ; a-c)$, BIB-expressing $(d-f)$, and HABIBexpressing $(g-i)$ oocytes. Traces show the current evoked by stepping to a series of voltages from +60 to $-90 \mathrm{mV}$ in $10 \mathrm{mV}$ increments from the holding potential of $-40 \mathrm{mV}$. The Initial current response was obtained before channel activation $(a, d, g)$. The Activated current response $(b, e, h)$ was obtained after BIB and HABIB channels were activated by endogenous signaling pathways. The Net Response $(c, f, i)$ was obtained by subtracting the set of initial traces from the final. Calibration: $2 \mu \mathrm{A}, 200$ msec. $B$, Time-dependent current activation in control and BIB- and HABIB-expressing oocytes. Data points show the current at $+40 \mathrm{mV}$ in response to repeated steps to $+40 \mathrm{mV}$ ( $800 \mathrm{msec}$ duration) every $5 \mathrm{sec}$ from the holding potential of $-40 \mathrm{mV}$. For clarity, the graph shows data at 5 min intervals. $C$, Rates of activation calculated for control $(8 \pm 12$ $\mathrm{nA} / \mathrm{min} ; n=10$; mean $\pm \mathrm{SD})$, BIB-expressing $(30 \pm 24 \mathrm{nA} / \mathrm{min} ; n=19)$, and HABIB-expressing (42 $\pm 42 \mathrm{nA} / \mathrm{min} ; n=22)$ oocytes. The rate of activation was calculated in the approximately linear range between 5 and 13 min from the slope of a linear fit of the current plotted as a function of time. The control group was significantly different (asterisk) from the $\mathrm{BIB}$ and HABIB groups, which were not significantly different from each other (Student's $t$ test, $p<0.05$ ). $D$, Net current-voltage relationship of
Maurel et al., 1995; Fushimi et al., 1997; Han et al., 1998b; Han and Patil, 2000). BIB contains consensus sites for phosphorylation (Burris et al., 1998) (see Fig. 6C). Therefore, we tested whether BIB was a target of endogenous signaling pathways present in the oocyte by pretreating oocytes with pharmacological agents that modify serine/threonine and tyrosine kinase pathways. The results of these experiments are shown in Figure 3.

Figure $3 A$ contains representative traces of HABIB-expressing and control oocytes after exposure to pharmacological agents that modify kinase-mediated signaling pathways in oocytes. Insulin is known to activate endogenous Xenopus insulin and insulin-like growth factor I (IGF-I) receptor-tyrosine kinases (Scavo et al., 1991); lavendustin A inhibits tyrosine kinases (O'Dell et al., 1991; Lawrence and Niu, 1998); H7 inhibits cAMP- and cGMPdependent protein kinases (Hidaka et al., 1984); and staurosporine inhibits protein kinase C (Kim et al., 2000; Volk et al., 2000). The initial traces represent the current responses immediately after electrode insertion, and the net response shows the current activated after $30 \mathrm{~min}$ of recording. Net conductance values were calculated from linear fits of the net response current-voltage relationships.

Figure 3 box plots summarize the net whole-cell conductance responses compiled for the same treatment conditions illustrated in Figure $3 A$. Oocytes were pretreated with $1 \mu \mathrm{M}$ staurosporine for $1 \mathrm{hr}$ (Kim et al., 2000; Volk et al., 2000) or in $10 \mu \mathrm{M} \mathrm{H} 7$ for 1-4 hr or were maintained in parallel without staurosporine or H7. Pretreatment with staurosporine had no effect on the net conductance response of BIB-expressing oocytes (Fig. 3B). A similar lack of effect was seen with incubation times up to $5 \mathrm{hr}$. Similarly, pretreatment with $\mathrm{H} 7$ had no effect on the net conductance response of BIB-expressing oocytes (Fig. 3B). No significant differences were observed when compared with the net conductance of untreated HABIB-expressing oocytes.

In contrast to the lack of effect of staurosporine and $\mathrm{H} 7$, pretreatment with insulin had a significant inhibitory effect on activation of HABIB-expressing oocytes (Fig. $3 C$ ). Insulin has been used to pharmacologically manipulate tyrosine kinase pathways in Xenopus oocytes and has been determined to modulate heterologously expressed proteins such as the inward rectifying potassium channel Kir2.1 (Wischmeyer et al., 1998), the NMDA receptor (Liao et al., 1999), the $\kappa$-opioid receptor (Appleyard et al., 2000), and the GLUT4 glucose transporter (Mora et al., 1995). The maximally effective dose of insulin in the oocyte expression system ranges from 0.8 to $10 \mu \mathrm{M}$ (Chuang et al., 1993; Andersen et al., 1998; Farah et al., 1998; Wischmeyer et al., 1998; Liao and Leonard., 1999; Appleyard et al., 2000). The high doses of insulin needed may reflect the contribution of endogenous insulin receptors as well as IGF-I receptors (which have a lower affinity for insulin) to the response in Xenopus oocytes (Hainaut et al., 1991; Scavo et al., 1991). The net whole-cell conductance after $20 \mu \mathrm{M}$ insulin pretreatment $(3 \pm 5 \mathrm{nA} / \mathrm{mV} ; n=14)$ remained at $<15 \%$

control (triangles; $n=10$ ), BIB-expressing (circles; $n=19$ ), and HABIBexpressing (squares; $n=22$ ) oocytes. $E$, Box plot summarizing the net conductance responses of control and BIB- and HABIB-expressing oocytes. The boxes enclose $50 \%$ of the data points; bars show the maximum and minimum data points, and the horizontal bar represents the median data value. Data for mean $\pm \mathrm{SD}$ and $(n)$ were as follows: control, $1 \pm 4$ (10); BIB, $17 \pm 11$ (19); and HABIB, $19 \pm 13$ (22). The control group was significantly different (asterisk) from the BIB and HABIB groups (two-tailed Student's $t$ test, $p<0.0001$ ). BIB and HABIB rates were not significantly different from each other. 
A. Initial

a.
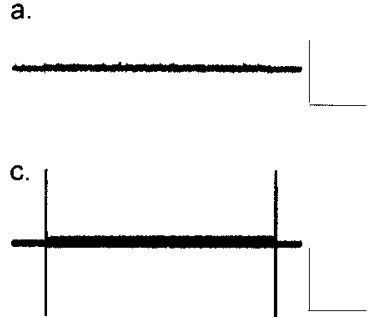

e.
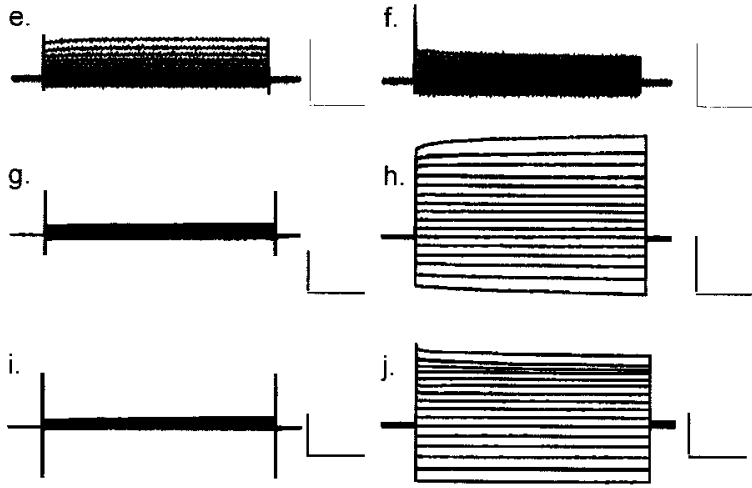

k.

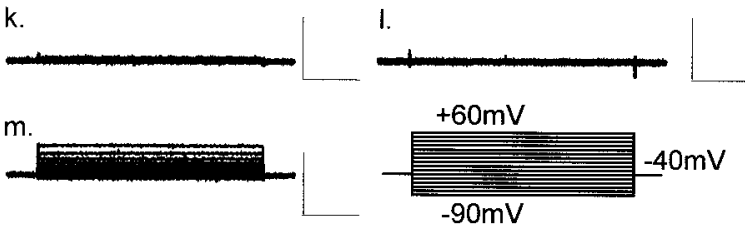

\section{Net Response}
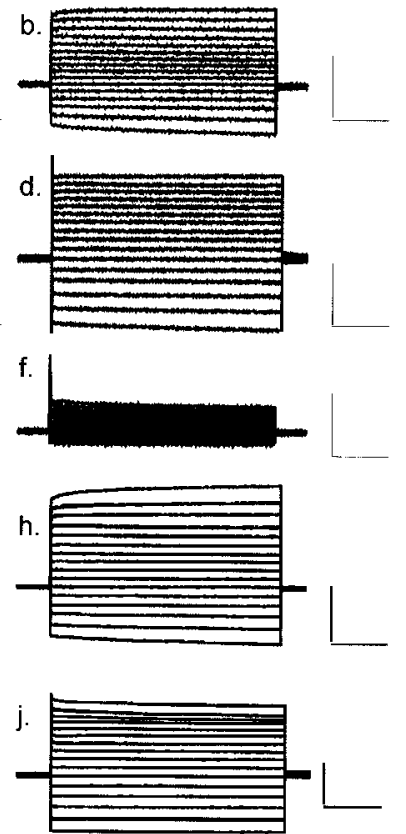

I.

$-90 \mathrm{mV}$
B.

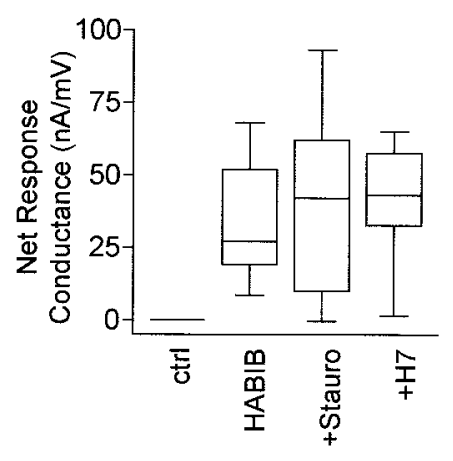

C.

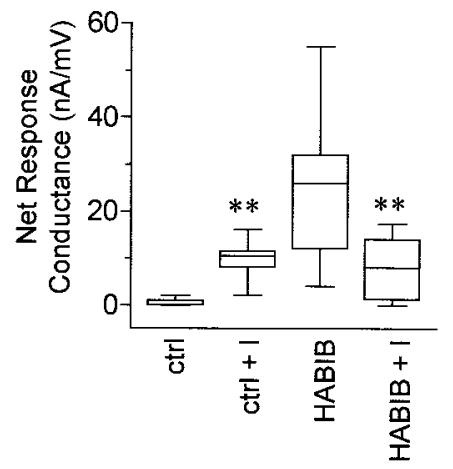

E.
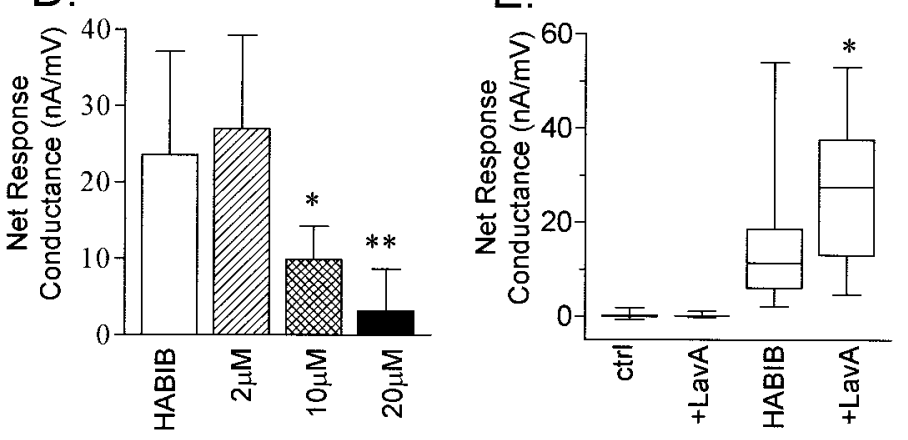

Figure 3. Regulators of kinase pathways differentially modulate the ionic conductance produced by electrode insertion and endogenous signaling in HABIB-expressing oocytes. $A$, Representative current traces for initial and net current responses measured from HABIB-expressing oocytes evoked by stepping to voltages from +60 to $-90 \mathrm{mV}$ in $10 \mathrm{mV}$ increments from a holding potential of $-40 \mathrm{mV}$. Calibration: $2.5 \mu \mathrm{A}$, $200 \mathrm{msec}$. Initial current responses were recorded immediately after electrode insertion $(a, c, e, g, i, k, m)$, and the Net Response currents were determined at 30 min after channel activation $(b, d, f, h, j, l)$. Initial and Net Response are shown for HABIB-expressing oocytes under standard conditions without pharmacological agents $(a, b)$, after $1 \mathrm{hr}$ of preincubation in $10 \mu \mathrm{M}$ lavendustin $\mathrm{A}(c, d)$, after $1 \mathrm{hr}$ of preincubation with $20 \mu \mathrm{M}$ insulin $(e, f)$, after 1 hr of pretreatment with 1 $\mu \mathrm{M}$ staurosporine $(g, h)$, and after $1 \mathrm{hr}$ of preincubation with $10 \mu \mathrm{M} \mathrm{H} 7(i, j)$. Initial and Net Response are shown for a control oocyte under standard conditions $(k, l)$ and after $1 \mathrm{hr}$ of preincubation with $20 \mu \mathrm{M}$ insulin $(m)$. B. Box plots summarize the effects of preincubation of HABIB-expressing oocytes with $1 \mu \mathrm{M}$ staurosporine (+Stauro) or $10 \mu \mathrm{M} \mathrm{H} 7(+H 7)$ on the net conductance of HABIB-expressing oocytes compared with untreated control oocytes $(\mathrm{ctrl})$. The boxes enclose $50 \%$ of the data points; vertical bars show the maximum and minimum; and the horizontal bar represents the median value. Data for mean \pm SD and $(n)$ are as follows: ctrl, $0 \pm 0$ (3); HABIB, $31 \pm 19$ (11); +Stauro, $40 \pm 31$ (12); and $+H 7,41 \pm 19$ (9). No significant differences were observed for treated and untreated HABIB-expressing oocytes. $C$, Box plots show the effect of preincubation of $20 \mu \mathrm{M}$ insulin $(+I)$ for $1 \mathrm{hr}$. Data for mean $\pm \mathrm{SD}$ and $(n)$ are as follows: ctrl, $1 \pm 1$ (13); ctrl $+I, 10 \pm 1$ (8); HABIB, $24 \pm 10$ (17); and HABIB + I, $3 \pm 5$ (14). Asterisks indicate a significant difference $(p<0.001)$ for insulin-treated HABIB-expressing oocytes compared with untreated HABIB-expressing oocytes and for insulin-treated versus untreated control oocytes. $D$, Bar graph showing the dose-dependent effect of insulin pretreatment $(2,10$, and $20 \mu \mathrm{M})$ on the net conductance of HABIB-expressing oocytes. Bar height indicates mean; error bars indicate SD. Data for mean \pm SD and ( $n$ ) are as follows: $H A B I B$, $24 \pm 10(17) ; 2 \mu \mathrm{M}, 27 \pm 12(5) ; 10 \mu \mathrm{M}, 10 \pm 4(6) ;$ and $20 \mu \mathrm{M}, 3 \pm 5(14)$. Asterisks indicate that HABIB-expressing oocytes treated with 10 or $20 \mu \mathrm{M}$ insulin had significantly smaller net conductances $(p<0.02)$ compared with those of HABIB-expressing oocytes that were untreated, or exposed to only $2 \mu \mathrm{M}$ insulin $\left({ }^{*} p<0.05{ }^{* *} p<0.01\right)$. E. Box plot summary of the responses of control and HABIB-expressing oocytes to 1 hr pretreatment with $10 \mu \mathrm{M}$ lavendustin A $(+$ LavA $)$. Data for mean \pm SD and $(n)$ are as follows: ctrl, $0.2 \pm 0.7$ (8); control + LavA, $0.3 \pm 0.5(5) ; H A B I B, 15 \pm 13(21)$; and HABIB + LavA, $27 \pm 15(18)$. The asterisk indicates significance $(p<0.05)$ for lavendustin A-treated HABIB-expressing oocytes compared with untreated HABIB-expressing oocytes (Student's $t$ test).

of that seen for untreated HABIB-expressing oocytes $(24 \pm 10$ $\mathrm{nA} / \mathrm{mV} ; n=17 ; p<0.001)$. Insulin inhibition of whole-cell conductance in HABIB-expressing oocytes was dose-dependent (Fig. 3D). The effect of insulin was not attributable indirectly to block of native oocyte currents. On the contrary, pretreatment with insulin activated a small conductance in HABIB-expressing oocytes that was also evident for control oocytes and thus attributed to endogenous oocyte channels. The small insulin-induced native current showed an outwardly rectifying current-voltage relationship, with a reversal potential of $-19 \pm 4 \mathrm{mV}(n=16)$; both features distinguished it from the HABIB-related conduc- tance, which had an approximately linear current-voltage relationship and a reversal potential of $-13 \pm 4 \mathrm{mV}$, significantly different from the insulin-induced native current $(n=17 ; p<$ 0.001). Insulin at $20 \mu \mathrm{M}$ effectively suppressed the current in HABIB-expressing oocytes to the level of control oocytes.

Lavendustin A is a tyrosine kinase inhibitor that is effective in oocytes (Molokanova et al., 1997). Pretreatment for $1 \mathrm{hr}$ with 10 $\mu \mathrm{M}$ lavendustin A significantly increased the net conductance of HABIB-expressing oocytes by $\sim 85 \%(27 \pm 15 \mathrm{nA} / \mathrm{mV} ; n=18)$ compared with untreated HABIB-expressing oocytes $(15 \pm 13$ $\mathrm{nA} / \mathrm{mV} ; n=21 ; p<0.05)$, but had no appreciable effect on 

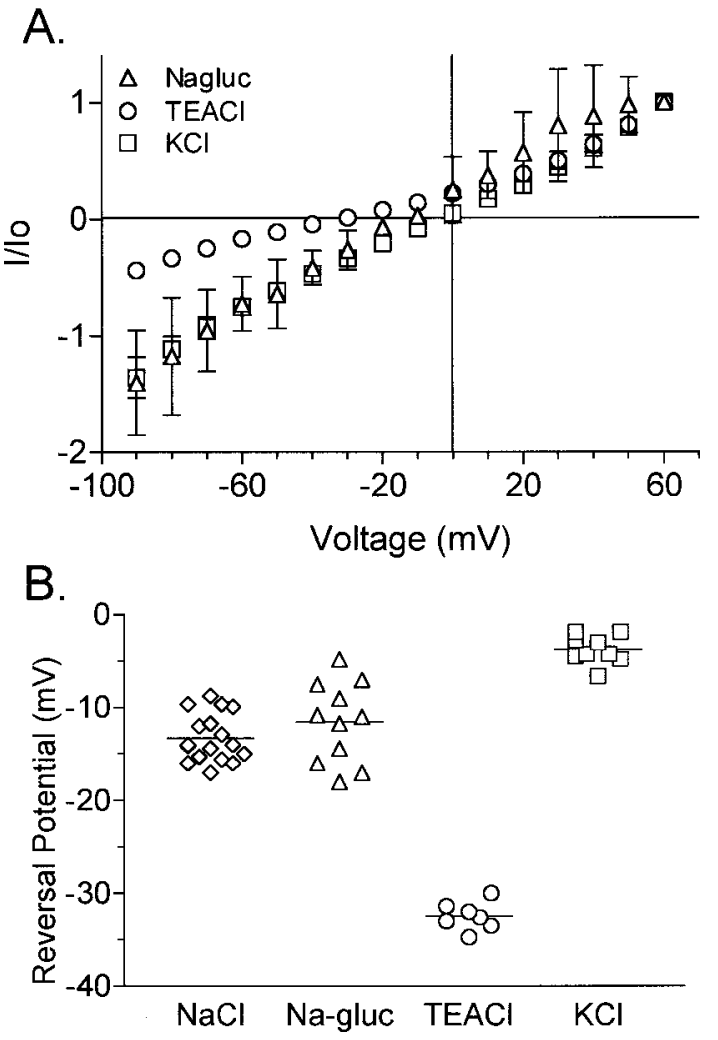

Figure 4. The BIB-associated ion conductance shows nonselective permeability to monovalent cations. $A$, Ionic selectivity was determined from the reversal potential of the current-voltage relationship of HABIBexpressing oocytes tested with iso-osmotic substitutions of $100 \mathrm{mM} \mathrm{NaCl}$ in bath saline with $100 \mathrm{~mm} \mathrm{KCl} \mathrm{(squares;} n=9$ ), $100 \mathrm{~mm}$ TEACl (circles; $n=7$ ), or $60 \mathrm{~mm} \mathrm{Na-gluconate} \mathrm{(Nagluc)} \mathrm{plus} 40 \mathrm{~mm} \mathrm{NaCl}$ (triangles; $n=$ $9)$. Currents $(I)$ were standardized to the outward current $\left(I_{o}\right)$ at +60 $\mathrm{mV}$. $B$, Calculated reversal potentials in BIB-expressing oocytes for currents recorded in bath salines containing $\mathrm{NaCl}$, Na-gluconate $(\mathrm{Na}$ gluc), TEACl, and $\mathrm{KCl}$, showing a selectivity sequence of $\mathrm{K}^{+}>\mathrm{Na}^{+}>$ TEA $^{+}$.

control oocytes (Fig. 2D). Thus the endogenous signaling pathway triggered by electrode insertion appears to involve tyrosine phosphorylation or dephosphorylation, consistent with studies of prick activation in oocytes (Sato et al., 1998; Glahn et al., 1999).

The current in BIB-expressing oocytes showed nonselective monovalent cation permeability (Fig. 4), analyzed by iso-osmotic substitution of $\mathrm{NaCl}$ in the bath recording saline. Figure $4 A$ shows current-voltage relationships for HABIB-expressing oocytes in various salines. Figure $4 B$ summarizes the reversal potentials measured for individual oocytes in each bath saline. Substitution of $100 \mathrm{~mm} \mathrm{NaCl}$ with equimolar $\mathrm{KCl}$ resulted in a significant depolarizing shift of the reversal potential from $-14 \pm$ $3 \mathrm{mV}(\mathrm{NaCl} ; n=17)$ to $-4 \pm 2 \mathrm{mV}(\mathrm{KCl} ; n=9 ; p<0.001)$. Substitution of $\mathrm{NaCl}$ with $100 \mathrm{~mm}$ tetraethylammonium chloride (TEACl; $n=7$ ) also significantly shifted the reversal potential to $-32 \pm 2 \mathrm{mV}(n=7 ; p<0.001)$. Partial substitution of $\mathrm{NaCl}$ with $60 \mathrm{~mm}$ sodium gluconate had no significant effect on reversal potential $(-11 \pm 5 \mathrm{mV} ; n=11)$, indicating no appreciable anionic permeability. Relative ionic permeability was calculated as described (see Materials and Methods) from the reversal potential and resulted in the following selectivity sequence: $P_{\mathrm{K}} / P_{\mathrm{K}}(1.0)>P_{\mathrm{Na}} / P_{\mathrm{K}}(0.71) \gg P_{\mathrm{TEA}} / P_{\mathrm{K}}(0.32)$.

Figure 5 shows that the expression of a nonfunctional mutant
HABIB channel protein does not induce increased membrane conductance in oocytes. The box plot data (Fig. $5 A$ ) summarize the responses of control oocytes, oocytes expressing wild-type HABIB, and E71N HABIB mutant channels. The mutation of Glu at position 71 in BIB to Asn (E71N) was one of a series of glutamate substitutions used to investigate putative cation binding sites (G. M. Yanochko and A. J. Yool, unpublished data). Mutation of $\mathrm{Glu}^{71}$ to Asn abolished the ionic conductance associated with BIB channels $(6 \pm 5 \mathrm{nA} / \mathrm{mV} ; n=17)$ compared with wild-type HABIB $(47 \pm 31 \mathrm{nA} / \mathrm{mV} ; n=13 ; p<0.001)$ but did not prevent trafficking to the plasma membrane. Figure $5 B$ shows the net current-voltage relationships measured in oocytes expressing wild-type HABIB $(n=13)$ and E71N HABIB $(n=17)$ and in control oocytes $(n=7)$. The current-voltage relationship of oocytes expressing E71N HABIB channels was not different from that of control oocytes. Figure $5 C$ shows representative responses for current activation as a function of time in oocytes expressing wild-type HABIB and E71N HABIB and in control oocytes. Only oocytes expressing HABIB showed development of current by spontaneous activation. Control oocytes and E71N HABIB-expressing oocytes showed no channel activation. The absence of a conductance response in E71N HABIB-expressing oocytes shows that the BIB-associated current is not an indirect consequence of heterologous protein expression in oocytes.

Immunofluorescent microscopy and Western blotting were used to determine the localization of E71N HABIB channels (Fig. 5D, $a-d$ ). Oocytes were labeled with a rat anti-HA antibody and an FITC-conjugated goat anti-rat secondary antibody. Images are shown in reverse field so that positive labeling is visualized as black staining. HA immunoreactivity was observed around the complete circumference of the oocyte in all $z$ sections analyzed for oocytes expressing HABIB and E71N HABIB. Control oocytes showed no labeling. Oocyte fractions enriched in plasma membranes were resolved by SDS-PAGE, and wild-type and E71N HABIB channels were visualized with antibodies to the HA epitope. Immunoreactive bands at $\sim 80 \mathrm{kDa}$, the expected size of HABIB channels, are seen in preparations from oocytes expressing wild-type and E71N mutant HABIB but not from control oocytes. Although we cannot rule out the possibility that E71N HABIB channels are located just below the plasma membrane, the similarities in patterns of circumferential immunoreactivity for wild-type and E71N HABIB and their similar localization in oocyte fractions enriched in plasma membranes strongly suggest that the nonfunctional E71N HABIB channels are successfully translated, transported, and expressed on the plasma membrane of the oocyte.

Figure 6 demonstrates that BIB is a substrate for tyrosine kinase phosphorylation. Proteins from control and HABIBexpressing oocytes were immunoprecipitated with rat-anti-HA antibody. After resolution by SDS-PAGE, proteins were transferred to nitrocellulose and probed with the rat-anti-HA antibody (Fig. 6A, top panel; to visualize BIB channels), anti-phosphotyrosine antibody (Fig. 6A, middle panel), or anti-phosphoserine antibody (Fig. $6 A$, bottom panel). As seen in Figure $6 A$, top panel, $\mathrm{BIB}$ channels are identified at the expected size of $80 \mathrm{kDa}$, whereas no proteins were visualized with HA antibody for proteins isolated from control oocytes. Reprobing the blot with anti-phosphotyrosine antibody revealed a band at $\sim 80 \mathrm{kDa}$ (Fig. $6 A$, middle panel, arrow) in protein preparations from BIBexpressing oocytes that was absent from control oocytes. A second band visualized with the phosphotyrosine antibody from BIB-expressing oocytes was also seen in control oocytes and is 

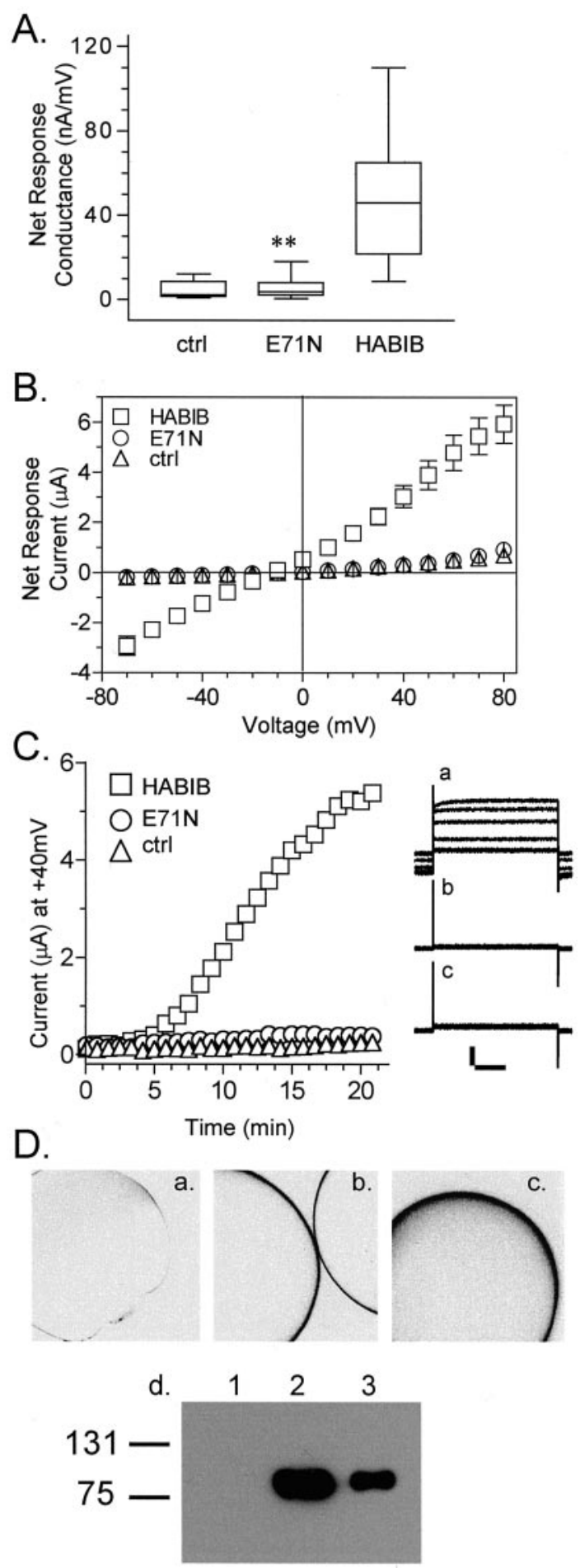

Figure 5. Mutation of HABIB (E71N) abolishes the ionic conductance response. $A$, The net conductance responses of control oocytes or oocytes expressing HABIB wild-type or E71N HABIB mutant channels are summarized as box plots. Net conductance values were obtained from the linear fits of the net current-voltage relationships. Data for mean \pm SD and $(n)$ are as follows: control (ctrl), $4 \pm 4$ (7); E71N, $6 \pm 5$ (17); and $H A B I B, 47 \pm$ 31 (13). Double asterisks indicate that the conductance of E71N-expressing oocytes was significantly reduced compared with that of HABIBexpressing oocytes $(\mathrm{p}<0.01)$ but not different from that of control oocytes. $B$, Mean net current-voltage relationships for wild-type HABIB-expressing (squares; $n=13$ ), E71N HABIB-expressing (circles; $n=17$ ), and control (triangles; $n=7$ ) oocytes. Data are mean $\pm \mathrm{SD}$. $C$, Activation of ionic current as a function of recording time in an oocyte expressing wild-type HABIB-expressing (squares; $n=13$ ) but not in E71N HABIB-expressing (circles; $n=17$ ) and control (triangles; $n=7$ ) oocytes. Data represent the likely to be attributable to nonspecific interactions. No bands were visualized at $\sim 80 \mathrm{kDa}$ for BIB-expressing or control oocytes after probing with the anti-phosphoserine antibody (Fig. $6 \mathrm{~A}$, bottom panel).

To confirm the tyrosine phosphorylation of BIB channels, we repeated these experiments by immunoprecipitating proteins from control (Fig. 6A, lanes 1, 3) or HABIB-expressing oocytes (Fig. 6A, lanes 2, 4) with either the anti-HA antibody or the phosphotyrosine antibody. A representative blot is shown in Figure $6 B$. After resolution by SDS-PAGE and transfer to nitrocellulose, proteins were visualized with the HA antibody. A band corresponding to $\sim 80 \mathrm{kDa}$ (the predicted size of $\mathrm{BIB}$ channels; arrow) is seen only from HABIB-expressing oocytes after immunoprecipitation with the HA and the phosphotyrosine antibody. No bands resolved at this size for protein from control oocytes. These results demonstrate that BIB channels are phosphorylated specifically at tyrosine residues. Figure $6 C$ summarizes the candidate sites for tyrosine phosphorylation in the $\mathrm{C}$-terminal sequence.

To test the role of the C-terminal domain as a possible site for BIB phosphorylation and modulation, a deletion mutation was constructed with truncation of the $\mathrm{C}$-terminal tail at position 317. Whereas the wild-type HABIB channel is $\sim 80 \mathrm{kDa}$, the expected size of $\Delta 317$ was $\sim 36 \mathrm{kDa}$. In Figure $7 A$, bands representing wild-type and $\Delta 317$ HABIB were visualized at the appropriate sizes in protein preparations isolated from plasma membrane fractions of oocytes (see Materials and Methods). Immunoprecipitations were performed with either the rat anti-HA antibody or with mouse anti-phosphotyrosine antibody; both blots were probed with anti-HA antibody. Both wild-type and $\Delta 317$ HABIB were detected in samples immunoprecipitated by the anti-HA antibody, but only wild-type HABIB was detected in samples immunoprecipitated with anti-phosphotyrosine antibody. These results indicated that the HABIB channels truncated at amino acid 317 are not appreciably phosphorylated on tyrosine residues.

The $\Delta 317$ truncation did not unmask a water permeability function of the BIB channel. An osmotic swelling assay in hypotonic saline showed that the relative volume of oocytes expressing $\Delta 317$ did not increase and remained similar to that of control oocytes for up to $10 \mathrm{~min}$ of exposure to hypotonic saline. The calculated osmotic water permeability $\left(P_{\mathrm{f}}\right)$ value for $\Delta 317$ was $2 \pm$ $6 \mu \mathrm{m} / \sec (n=4)$ and was not significantly different from that of control oocytes $(2 \pm 1 \mu \mathrm{m} / \mathrm{sec} ; n=4)$. As a positive control, comparable assays of AQP1-expressing oocytes yielded significant osmotic water permeability, with a $P_{\mathrm{f}}$ value of $26 \pm 13$ $\mu \mathrm{m} / \sec (n=5)$.

As shown in Figure $3 E$, the net conductance response of oocytes expressing wild-type HABIB was enhanced significantly

$\leftarrow$

current amplitude at $+40 \mathrm{mV}$ evoked byrepeated steps (800 msec duration) every $5 \mathrm{sec}$ from a holding potential of $-40 \mathrm{mV}$. For clarity, data points are shown at 1 min intervals. Inset, Corresponding current traces evoked by repeated steps to $+40 \mathrm{mV}$ are shown at $\sim 4$ min intervals for HABIB-expressing $(a)$, control $(b)$, and E71N-expressing $(c)$ oocytes. $D$, Confocal images of a control oocyte $(a)$ and oocytes expressing HABIB (b) or E71N (c), all labeled with a rat anti-HA antibody (Roche Molecular Biochemicals) and visualized by a fluorescein isothiocyanateconjugated secondary antibody by confocal microscopy. Images are shown in reverse field for clarity. $d$, Western blot of plasma membrane fractions from control oocytes (lane 1) and oocytes expressing wild-type HABIB (lane 2) or E71N HABIB channels (lane 3). Bands at $\sim 80 \mathrm{kDa}$, the expected size of HABIB channels, were visualized with the HA antibody (clone 3F10). The mutation does not appear to prevent membraneassociated expression of HABIB E71N channels in oocytes. 

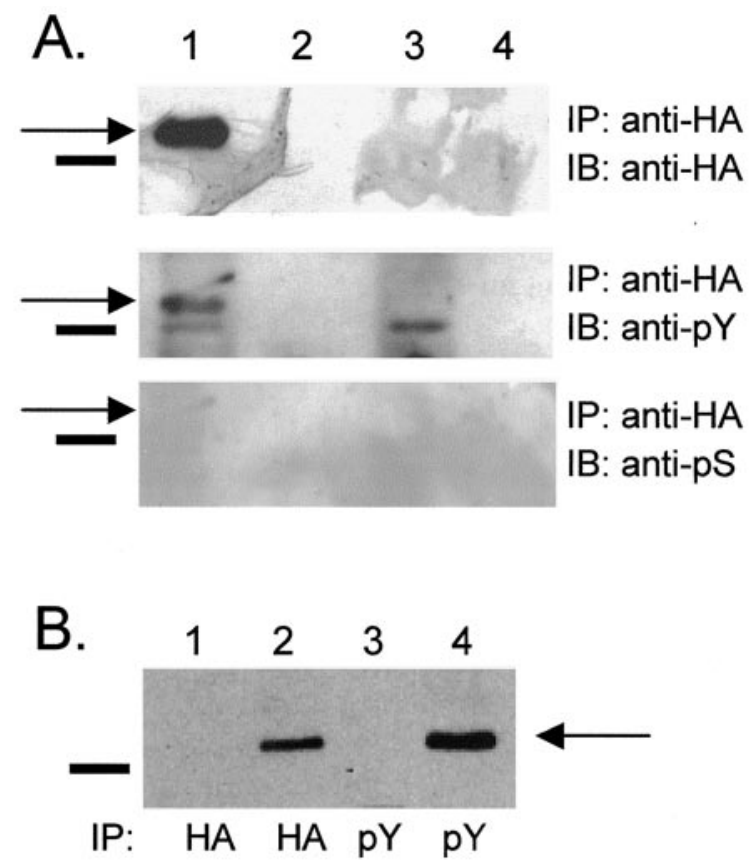

C.

$\frac{269}{\text { SGLVYEYIFNSRNRNLRHNKGS IDNDSSSIHSEDELNY }}$
$\star$
DMDMEKPNKYQQSQGTYPRGQSNGNGGGQAAGNGQHQA
ANMGQMPGVVANAGQGNYCQNLYTAPPLSSKYDQQQEP
$\frac{\text { LYGGTRSLYCRSPTLTRSNLNRSQSVYAKSNTAINRDI }}{\star}$
VPRPGPLVPAQSLYPMRTQQQQQQQQQQQQQVASAPQS
SHLQNQNVQNQMQQRSESIYGMRGSMRGQQQPIQQQQQ
$\star$
QQQQQLQQQQPNMGVQQQQMQPPPQMMSDPQQQPQGFQ
PVYGTRTNPTPMDGNHKYDRRDPQQMYGVTGPRNRGQS
AQSDDSSYGSYHGSAVTPPARHPSVEPSPPPPPMLMYA
PPPQPNAAHPQPIRTQSERKVSAPVVVSQPAACAVTYT
$\frac{\text { TSQGSAVTAQQQQQQQQQQQQQQQQQQQQQQQQQMMMQ }}{\text { QQQQHYGMLPLRPN-700 }}$

Figure 6. HABIB channels are phosphorylated on tyrosine residues. $A$, Plasma membrane-enriched fractions from HABIB-expressing oocytes (lane 1) or control oocytes (lane 3) were immunoprecipitated (IP) with anti-HA antibody. Proteins immunoprecipitated with anti-HA antibody from cytosolic fractions are shown in lane 2 (HABIB-expressing oocytes) and lane 4 (control oocytes). The blot was probed by immunoblotting (IB) with antibody to HA (top panel), antibody to phosphorylated tyrosine (PY11120; anti-pY, middle panel), and antibody to phosphorylated serine (anti-pS, bottom panel). Solid bars show the position of the $75 \mathrm{kDa}$ molecular marker. Arrows show BIB channels at the expected size of $\sim 80$ $\mathrm{kDa}$. B, Plasma membrane fractions from control (lanes 1, 3) or HABIBexpressing oocytes (lanes 2, 4) were immunoprecipitated with either the HA antibody or PY11120 antibody. The blot was probed with HA antibody to show the presence of the BIB channels. $C$, In the $\mathrm{C}$-terminal tail of BIB (amino acids 269-700), potential sites of tyrosine phosphorylation by src are indicated by an asterisk, and those for Abl are indicated by an apostrophe. Sequences that influence sites for tyrosine phosphorylation are underlined; residues that correspond to optimal kinase substrates are bold (Songyang et al.; 1995). Potential SH3 binding domains (P-X-X-P) are gray (Koch et al., 1991; Rickles et al., 1994; Cohen et al., 1995). by pretreatment with the tyrosine kinase inhibitor lavendustin $\mathrm{A}$. The effect of C-terminal tail truncation on the modulatory effect of tyrosine kinase signaling pathways was tested with lavendustin A treatment (Fig. 7B). One hour of incubation with $10 \mu \mathrm{M}$ lavendustin A did not enhance the conductance of oocytes expressing $\Delta 317(7 \pm 3 \mathrm{nA} / \mathrm{mV} ; n=8)$ and was not significantly different from untreated $\Delta 317$-expressing oocytes $(6 \pm 2 \mathrm{nA} / \mathrm{mV}$; $n=8)$. This result suggests that truncation of the $\mathrm{C}$-terminal tail at amino acid 317 removes a component of regulation by endogenous tyrosine kinase signaling pathways and supports the hypothesis that one or more sites within amino acids 317-700 are targets of tyrosine phosphorylation that contribute in part to BIB channel modulation.

Oocytes expressing $\Delta 317$ showed a lower maximal current amplitude $(6 \pm 5 \mathrm{nA} / \mathrm{mV} ; n=23)$ compared with wild type $(22 \pm$ $14 \mathrm{nA} / \mathrm{mV} ; n=30)$, but the response with $\Delta 317$ was significantly greater than that of control oocytes $(2 \pm 2 \mathrm{nA} / \mathrm{mV} ; n=21 ; p<$ $0.05)$. These results suggest that there may be multiple domains within the truncated region of the BIB C terminus that have both positive and negative effects on channel function or assembly. The reversal potential of the net conductance response in HABIB $\Delta 317(-18 \pm 8 \mathrm{mV} ; n=22)$ was not significantly different from that of wild-type HABIB $(-19 \pm 8 \mathrm{mV} ; n=24)$. The ability of $\Delta 317$ channels to show an ionic conductance response, albeit at a reduced maximal amplitude, indicates that the essential mechanism of channel activation is retained either in the proximal region of the $\mathrm{C}$-terminal tail or in another structural domain of the BIB channel not directly affected by the truncation mutation.

\section{DISCUSSION}

The results presented in this article demonstrate that Xenopus oocytes expressing Drosophila BIB acquire a nonselective cation channel function. Channel activation measured by voltage clamp is regulated by a mechanism involving endogenous signaling pathways triggered by electrode insertion and dependent on tyrosine phosphorylation but not serine/threonine phosphorylation. BIB is shown by Western blot analysis to be a target for tyrosine phosphorylation but not serine phosphorylation. Pharmacological stimulation of tyrosine kinase pathways within the oocyte using insulin effectively abolished the conductance of BIB-expressing oocytes. Conversely, treatment with lavendustin A, a tyrosine kinase inhibitor, increased the net conductance of BIBexpressing oocytes. Partial truncation of the BIB C terminus impaired tyrosine phosphorylation and the effects of lavendustin A. Taken together, these data support the conclusion that the ionic conductance is mediated directly by the BIB protein.

The effect of insulin in Xenopus oocytes and neuronal cells can be mediated through cascades involving phospholipase $\mathrm{C}$, phosphatidylinositol-3 kinase, and protein kinase C (Garcia de Herreros et al., 1991; Gould et al., 1994; Liu et al., 1995; Mora et al., 1995; Liao and Leonard, 1999; Puglianiello et al., 2000); however, the step that mediates the direct phosphorylation at the BIB channel itself is not identified in this work. The current activation and conductance responses were absent from control oocytes or, in the case of insulin, opposite to that seen for the BIB-associated ionic conductance.

The method used here for activation of ion channel function in BIB-expressing oocytes by electrode insertion appears unusual but may be related to a well known phenomenon of parthenogenic oocyte activation that mimics fertilization. Sperm entry and as well as artificial stimulation by pricking, electric shock, and chemicals 


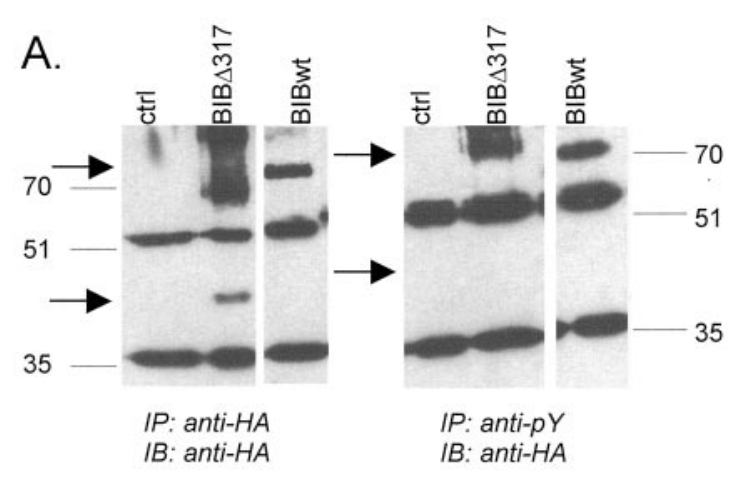

B.

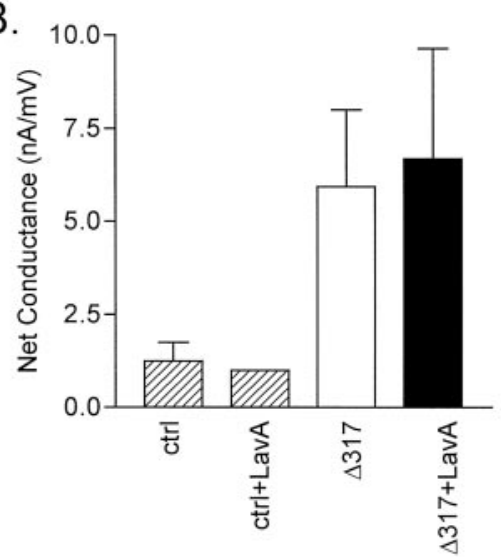

Figure 7. Truncation of the C-terminal tail removes detectable tyrosine phosphorylation of BIB and prevents potentiation of the net conductance response by a tyrosine kinase inhibitor. $A$, Western blot of proteins immunoprecipitated $(I P)$ from oocyte plasma membrane fractions with a rat anti-HA antibody (clone 3F10, Roche Molecular Biochemicals; left) or a mouse anti-phosphotyrosine (anti-pY) antibody (PY11120, Transduction Laboratories; right). Both blots were probed with the rat anti-HA antibody $(I B)$ and goat anti-rat IgG HRP-conjugated secondary antibody. HA-tagged BIB constructs (HABIB and $\Delta 317$ ) were visualized by enhanced chemiluminescence (Pierce). Shown are proteins from control, $\Delta 317$, and wild-type HABIB-expressing oocytes (arrows). Wild-type HABIB is phosphorylated on tyrosine residues, but $\Delta 317$ is not measurably phosphorylated. $B$, Summary of data showing the lack of effect of pretreatment with $10 \mu \mathrm{M}$ lavendustin A $(\operatorname{Lav} A)$ on oocytes expressing $\Delta 317$ HABIB. Bar height indicates mean conductance, and error bars indicate SD. In contrast to the significant effect on wild-type channels (Fig. 3E), no differences were observed between lavendustin A-treated and untreated oocytes expressing $\triangle 317 \mathrm{HABIB}$. Data for mean $\pm \mathrm{SD}$ and $(n)$ are as follows: control $(c t r l), 1 \pm 0.5$ (4); ctrl $+\operatorname{Lav} A, 1 \pm 0(2) ; \Delta 317$, $6 \pm 2(8) ;$ and $\Delta 317+\operatorname{Lav} A, 7 \pm 3$ (8).

trigger intracellular kinase signaling pathways in oocytes that mediate cell cycle progression in a process termed "oocyte activation" (Wolf, 1974; Ferrell, 1999). Although the oocytes used for heterologous expression are not as mature, it is reasonable to hypothesize that the kinase-sensitive activation of BIBexpressing oocytes by electrode penetration may occur by an analogous mechanism. Artificially stimulated oocytes show both activation and inactivation of different kinases, including the src-related p57 Xenopus tyrosine kinase, c-Jun N-terminal kinase, $\mathrm{Eg} 2$, cdc2K, and mitogen-activated protein kinase (Sato et al., 1996; Ferrell, 1999; Frank-Vaillant et al., 2000; Bagowski et al., 2001). The relevant signaling pathway for studies described here remains to be defined, but pharmacological assays indicate the likely candidates include tyrosine kinases.

Four lines of evidence demonstrate that the current we observed in BIB-expressing oocytes is mediated by BIB channels and not by unidentified oocyte channels: (1) there is a lack of a conductance response from control oocytes; (2) mutation of Glu at position 71 to Asn (E71N) resulted in nonfunctional channels that appear to be expressed on the plasma membrane but do not recruit any ionic conductance response; (3) mechanisms of activation differ for the ionic conductance responses mediated by various channels in the MIP family, including AQP1 (activated by cGMP), AQP6 (activated by acidic pH), and BIB (regulated by tyrosine phosphorylation) when expressed in oocytes (Yasui et al., 1999; Anthony et al., 2000; and data presented here); and (4) partial truncation of the $\mathrm{C}$-terminal tail domain interferes with tyrosine phosphorylation and pharmacological modulation of the current in BIB-expressing oocytes. In addition, preliminary results from cell-attached patch-clamp experiments of BIB-expressing oocytes have revealed a large, novel single-channel conductance (300 \pm $30 \mathrm{pS}$, mean $\pm \mathrm{SD}$; Yanochko and Yool, unpublished observations) not seen in control oocytes. Large single-channel conductances have been observed in other MIP family ion channels: 145 pS for AQP1 (Anthony et al., 2000) and 380 pS for AQP0 (Ehring et al., 1990).

We have shown that the BIB protein is a target of tyrosine phosphorylation in oocytes and that the conductance associated with BIB expression is enhanced by lavendustin A, a tyrosine kinase inhibitor, and decreased by insulin, which acts on endogenously expressed insulin receptor and IGF-I tyrosine kinase receptors (Hainaut et al., 1991; Scavo et al., 1991). These data support a model in which signals promoting dephosphorylation enhance BIB ion channel activation. Alternatively, BIB channels may associate with other proteins that are modulated by tyrosine phosphorylation and dephosphorylation. Several different mechanisms may regulate $\mathrm{BIB}$ ion channel activity, because the $\mathrm{C}$ terminal tail contains many additional sites of potential regulatory interactions, including consensus sequences for phosphorylation by serine/threonine kinases (Burris et al., 1998), polyglutamine stretches (Rao et al., 1990), and three internal PSD-95, Drosophila Discs large, zona-occludens-1 (PDZ) binding domains. Although insulin and IGF-I receptors signal through many pathways, including tyrosine phosphatases in oocytes (Savchenko et al., 2001), serine/threonine kinase pathways do not appear to be involved in the regulation of BIB in oocytes on the basis of the lack of effects of $\mathrm{H} 7$ and staurosporine.

The lack of tyrosine phosphorylation of $\Delta 317$ HABIB and the lack of effect of lavendustin A on these channels suggests that the C-terminal tail between amino acids 317 and 700 contributes to tyrosine kinase modulation of HABIB in Xenopus oocytes. There are multiple regulatory domains in the $\mathrm{C}$-terminal tail, including putative Src homology 3 (SH3) and PDZ binding domains and polyglutamines that may affect protein-protein interactions and mechanisms of regulation in addition to tyrosine phosphorylation. The C-terminal tail of BIB contains two elements important for regulation by tyrosine kinases: tyrosine residues and $\mathrm{SH} 3$ binding domains (Fig. 6C). Twenty-two tyrosine residues are located on intracellular portions of the BIB channel: 1 in the $\mathrm{N}$ terminus and 21 in the $C$ terminus (Rao et al., 1990). Ongoing experiments are aimed at identifying the specific tyrosine residues involved in modulation of BIB channel activity; however, on the basis of optimal sequences for phosphorylation (Fig. 6C) (Songyang et al., 1995), 5 of the 21 tyrosines in the C-terminal tail of BIB are likely candidates for phosphorylation by tyrosine kinases such as src or Abl. In the BIB sequence shown in Figure $5 C$, the three tyrosines that may be targets for $\operatorname{src}\left(\mathrm{Tyr}^{273}, \mathrm{Tyr}^{384}\right.$, and $\mathrm{Tyr}^{478}$ ) are labeled with an asterisk below the sequence, those 
for $\mathrm{Abl}\left(\mathrm{Tyr}^{367}\right.$ and $\left.\mathrm{Tyr}^{609}\right)$ are indicated by an apostrophe, and the six amino acids flanking the site of potential tyrosine phosphorylation are underlined, with those conforming to the optimal sequence suggested by Songyang et al. (1995) highlighted in bold. All but $\mathrm{Tyr}^{273}$ are surrounded by three amino acids that match the sequence for optimal substrates for src and Abl, as determined by Songyang et al. (1995).

In addition to putative sites of tyrosine phosphorylation, the C-terminal tail contains four potential SH3 binding domains, proline-rich sequences that mediate protein interactions, notably between tyrosine kinases and their substrates (Fig. 5C). For example, for both hKv1.5 and connexin 43, intact SH3 binding domains are critical for regulatory interaction of the channels with src (Holmes et al., 1996; Kanemitsu et al., 1997). SH3 binding domains present in the BIB C-terminal tail domain may mediate the interactions between tyrosine kinases and BIB channels.

The properties of BIB channels and the nature of their regulation during Drosophila neurogenesis clearly need to be investigated. Our finding that BIB expression results in a regulated cationic channel function in Xenopus oocytes suggests that BIB activation in vivo would result in membrane depolarization. Results obtained by Goodman and Spitzer (1979) from grasshopper embryos support this idea; the resting membrane potentials of differentiated neuroblasts were -60 to $-80 \mathrm{mV}$, whereas those of surrounding non-neural cells were slightly depolarized, ranging from -40 to $-60 \mathrm{mV}$.

Both tyrosine kinases and phosphatases are involved in neuronal development in Drosophila (Fernandez et al., 1995; Skeath, 1998; Miller et al., 2000). Although we did not test for an interaction between insulin or IGF-I receptors and BIB in Drosophila, it is interesting that Drosophila embryos carrying mutations in the insulin receptor lacked populations of both neurons and glia, suggesting a role of the Drosophila insulin receptor in neurogenesis (Fernandez et al., 1995). In this sense, the Xenopus oocyte may have provided a better model system for evaluating BIB regulation than was expected. Further experiments are needed to determine the importance of the putative ion channel function of BIB in Drosophila neuronal development and the Notch signaling pathway, the role of membrane depolarization mediated by BIB in cell fate determination, and the relationship between the insulin receptor tyrosine kinase and BIB channel regulation in vivo.

Our data support the hypothesis that BIB forms a nonselective cation channel when expressed in Xenopus oocytes. Our novel finding that the BIB-mediated conductance is regulated by a mechanism involving tyrosine kinase pathways appears to fit logically with the role of BIB in neurogenesis, a process that is governed by growth factors and other environmental cues (Pimentel et al., 1996; Kimble and Simpson, 1997; Skeath, 1998; Udolph et al., 1998; Chen et al., 1999). The nature of the native regulation of BIB in Drosophila and the relationship between ion channel activity and the Notch signaling pathway remain to be determined. Further studies into the functional domains of the BIB protein should provide more clues to the unique involvement of $b i b$ in neurogenesis and further evidence of the diversity of function in the MIP family of channels.

\section{REFERENCES}

Adams MD, Dubnick M, Kerlavage AR, Moreno R, Kelley JM, Utterback TR, Nagle JW, Fields C, Venter JC (1992) Sequence identification of 2,375 human brain genes. Nature 355:632-634.

Andersen CB, Roth RA, Conti M (1998) Protein kinase B/Akt induces resumption of meiosis in Xenopus oocytes. J Biol Chem 273:1870518708.

Anthony TL, Brooks HL, Boassa D, Leonov S, Yanochko GM, Regan JW, Yool AJ (2000) Cloned human Aquaporin-1 is a cyclic-GMPgated ion channel. Mol Pharmacol 57:576-588.

Appleyard SM, McLaughlin JP, Chavkin C (2000) Tyrosine phosphorylation of the $\kappa$-opioid receptor regulates agonist efficacy. J Biol Chem 275:38281-38285.

Artavanis-Tsakonas S, Matsuno K, Fortini ME (1995) Notch signaling. Science 268:225-232.

Artavanis-Tsakonas S, Rand MD, Lake RJ (1999) Notch signaling: cell fate control and signal integration in development. Science 284:770776 .

Bagowski CP, Xiong W, Ferrell Jr JE (2001) c-Jun N-terminal kinase activation in Xenopus laevis eggs and embryos. J Biol Chem 276:14591465.

Bailey AM, Posakony JW (1995) Suppressor of Hairless directly activates transcription of Enhancer of split complex genes in response to Notch receptor activity. Genes Dev 9:2609-2622.

Brand M, Campos-Ortega JA (1988) Two groups of interrelated genes regulate early neurogenesis in Drosophila melanogaster. Wilhelm Rouxs Arch Dev Biol 197:457-470.

Burris PA, Zhang Y, Rusconi JC, Corbin V (1998) The pore-forming and cytoplasmic domains of the neurogenic gene product, Big Brain are conserved between Drosophila virilis and Drosophila melanogaster. Gene 206:69-76.

Chen C, Jack J, Garofalo RS (1999) The Drosophila insulin receptor is required for normal growth. Endocrinology 137:846-856.

Chuang, L-M, Martin Jr MG, Seidner GA, Birnbaum MJ, White MF, Kahn CR (1993) Insulin receptor substrate 1 mediates insulin and insulin-like growth factor I-stimulated maturation of Xenopus oocytes. Proc Natl Acad Sci USA 90:5172-5175.

Cohen GB, Ren R, Baltimore D (1995) Modular binding domains in signal transduction proteins. Cell 80:237-248.

de la Concha A, Dietrich U, Weigel D, Campos-Ortega JA (1988) Functional interactions of neurogenic genes of Drosophila melanogaster. Genetics 118:499-508.

Delidakis C, Artavanis-Tsakonas S (1992) The Enhancer of split [E(spl)] locus of Drosophila encodes seven independent helix-loop-helix proteins. Proc Natl Acad Sci USA 89:8731-8735.

Doherty D, Jan LY, Jan YN (1997) The Drosophila neurogenic gene big brain, which encodes a membrane-associated protein, acts cell autonomously and can act synergistically with Notch and Delta. Development 124:3881-3893.

Ehring GR, Zampighi GA, Horwitz J, Bok D, Hall JE (1990) Properties of channels reconstituted from the major intrinsic protein of lens fiber membranes. J Gen Physiol 96:631-664.

Ehring GR, Lagos N, Zampighi GA, Hall JE (1991) Phosphorylation modulates the voltage dependence of channels reconstituted from the Major Intrinsic Protein of lens fiber membranes. J Membr Biol 126:75-88.

Farah S, Agazie Y, Ohan N, Ngsee JK, Liu XJ (1998) A Rho-associated protein kinase, $\mathrm{ROK} \alpha$, binds insulin receptor substrate-1 and modulates insulin signaling. J Biol Chem 273:4740-4746.

Fehon RG, Kooh PJ, Rebay I, Regan CL, Xu T, Muskavitch MAT, Artavanis-Tsakonas S (1990) Molecular interactions between the protein products of the neurogenic loci Notch and Delta, two EGFhomologous genes in Drosophila. Cell 61:523-534.

Fernandez R, Tabarini D, Azpiazu N, Frasch M, Schlessinger J (1995) The Drosophila insulin receptor homolog: a gene essential for embryonic development encodes two receptor isoforms with different signaling potential. EMBO J 14:3373-3384.

Ferrell Jr JE (1999) Xenopus oocyte maturation: new lessons from a good egg. BioEssays 21:833-842.

Fortini ME, Artavanis-Tsakonas S (1994) The Suppressor of Hairless protein participates in Notch receptor signaling. Cell 79:273-282.

Frank-Vaillant M, Haccard O, Thibier C, Ozon R, Arlot-Bonnemains Y, Prigent C, Jessus C (2000) Progesterone regulates the accumulation and the activation of Eg2 kinase in Xenopus oocytes. J Cell Sci 113:1127-1138.

Fushimi K, Sasaki S, Marumo F (1997) Phosphorylation of serine 256 is required for cAMP-dependent regulatory exocytosis of the aquaporin-2 water channel. J Biol Chem 272:14800-14804.

Garcia de Herreros A, Dominguez I, Diaz-Meco MT, Graziani G, Cornett ME, Guddal PH, Johansen T, Moscat J (1991) Requirement of phospholipase C-catalyzed hydrolysis of phosphatidylcholine for maturation of Xenopus laevis oocytes in response to insulin and ras p21. J Biol Chem 266:6825-6829.

Geering K, Theulaz I, Verrey F, Häuptle T, Rossier BC (1989) A role for the $\beta$-subunit in the expression of functional $\mathrm{Na}^{+}-\mathrm{K}^{+}$ATPase in Xenopus oocytes. Am J Physiol 257:C851-C858.

Glahn D, Mark SD, Behr RK, Nuccitelli R (1999) Tyrosine kinase inhibitors block sperm-induced egg activation in Xenopus laevis. Dev Biol 205:171-180.

Goodman CS, Spitzer NC (1979) Embryonic development of identified 
neurones: differentiation from neuroblast to neurone. Nature 280:208214.

Goriely A, Dumont N, Dambly-Chaudière C, Ghysen A (1991) The determination of sense organs in Drosophila: effect of the neurogenic mutations in the embryo. Development 113:1395-1404.

Gould GW, Jess TJ, Andrews GC, Herbst JJ, Plevin RJ, Gibbs EM (1994) Evidence for a role of phosphatidylinositol 3-kinase in the regulation of glucose transport in Xenopus oocytes. J Biol Chem 269:26622-26625.

Greenspan RJ (1992) Initial determination of the neurectoderm in Drosophila. In: Determinants of neuronal identity (Shankland M, Macagno ER, eds), pp 155-188. New York: Academic.

Hainaut P, Kowalski A, Giorgetti S, Baron V, Van Obberghen E (1991) Insulin and insulin-like-growth-factor-I (IGF-I) receptors in Xenopus laevis oocytes: comparison with insulin receptors from liver and muscle. Biochem J 273:673-678.

Han Z, Patil RV (2000) Protein kinase A-dependent phosphorylation of Aquaporin-1. Biochem Biophys Res Commun 273:328-332.

Han Z, Wax MB, Patil RV (1998a) Potential role of aquaporins and atrial natriuretic peptides in the aqueous humor dynamics. Exp Eye Res 67:251-253.

Han Z, Wax MB, Patil RV (1998b) Regulation of Aquaporin-4 water channels by phorbol ester-dependent protein phosphorylation. J Biol Chem 273:6001-6004.

Hidaka H, Inagaki M, Kawamoto S, Sasaki Y (1984) Isoquinolinesulfonamides, novel and potent inhibitors of cyclic nucleotide dependent protein kinase and protein kinase C. Biochemistry 23:5036-5041.

Hille B (1992) Ionic channels of excitable membranes. Sunderland, MA: Sinauer.

Holmes TC, Fadool DA, Ren R, Levitan IB (1996) Association of src tyrosine kinase with a human potassium channel mediated by $\mathrm{SH} 3$ domain. Science 274:2089-2091.

Kanemitsu MY, Loo LW, Lau AF, Eckhart W (1997) Tyrosine phosphorylation of connexin 43 by v-src is mediated by SH2 and SH3 domain interactions. J Biol Chem 272:22824-22831.

Kim M-J, Lee Y-S, Han J-K (2000) Modulation of lysophosphatidic acid-induced $\mathrm{Cl}^{-}$currents by protein kinases $\mathrm{A}$ and $\mathrm{C}$ in the Xenopus oocyte. Biochem Pharmacol 59:241-247.

Kimble J, Simpson P (1997) The LIN-12/Notch signaling pathway and its regulation. Annu Rev Cell Dev Biol 13:333-361.

Koch CA, Anderson D, Moran MF, Ellis C, Pawson T (1991) SH2 and SH3 domains: elements that control interactions of cytoplasmic signaling proteins. Science 252:668-674.

Kubota HY, Yoshimoto Y, Yoneda M, Hiramoto Y (1987) Free calcium wave upon activation in Xenopus eggs. Dev Biol 119:129-136.

Lai EC, Bodner R, Kavaler J, Freschi G, Posakony JW (2000) Antagonism of Notch signaling activity by members of a novel protein family encoded by the Bearded and Enhancer of split gene complexes. Development 127:291-306.

Lawrence DS, Niu J (1998) Protein kinase inhibitors: the tyrosinespecific protein kinases. Pharmacol Ther 77:81-114.

Lehmann R, Jimenez F, Dietrich U (1983) On the phenotype and development of mutants of early neurogenesis in Drosophila melanogaster. Wilhelm Rouxs Arch Dev Biol 192:62-74.

Liao G-Y, Leonard JP (1999) Insulin modulation of cloned mouse NMDA receptor currents in Xenopus oocytes. J Neurochem 73:15101519.

Liu, L, Brown III JC, Webster WW, Morrisett RA, Monaghan DT (1995) Insulin potentiates $N$-methyl-D-aspartate receptor activity in Xenopus oocytes and rat hippocampus. Neurosci Lett 192:5-8.

Maurel C, Kado RT, Guern J, Chrispeels MJ (1995) Phosphorylation regulates the water channel activity of the seed-specific aquaporin $\alpha$-TIP. EMBO J 14:3028-3035.

Miller DT, Read R, Rusconi J, Cagan RL (2000) The Drosophila primo locus encodes two low-molecular weight tyrosine phosphatases. Gene 243:1-9.

Molokanova E, Trivedi B, Savchenko A, Kramer RH (1997) Modulation of rod photoreceptor cyclic nucleotide-gated channels by tyrosine phosphorylation. J Neurosci 17:9068-9076.

Mora S, Kaliman P, Chillaron J, Testar X, Palacin M, Zorzano A (1995) Insulin and insulin-like growth factor (IGF-I) stimulate GLUT4 glucose transporter translocation in Xenopus oocytes. Biochem $\mathrm{J}$ 311:59-65

O'Dell TJ, Kandel ER, Grant SGN (1991) Long-term potentiation in the hippocampus is blocked by tyrosine kinase inhibitors. Nature 353:558560.

Pimentel, B, de la Rosa EJ, De Pablo F (1996) Insulin acts as an embryonic growth factor for Drosophila neural cells. Biochem Biophys Res Commun 226:855-861.
Preston GM, Carroll TP, Guggino WB, Agre P (1992) Appearance of water channels in Xenopus oocytes expressing red cell CHIP28 protein. Science 256:385-387.

Puglianiello A, Germani D, Rossi P, Cianfarani S (2000) IGF-I stimulates chemotaxis of human neuroblasts. Involvement of type 1 IGF receptor, IGF binding proteins. J Endocrinol 165:123-131.

Rao Y, Jan LY, Jan YN (1990) Similarity of the product of the Drosophila neurogenic gene big brain to transmembrane channel proteins. Nature 345:163-167.

Rao Y, Bodmer R, Jan LY, Jan YN (1992) The big brain gene of Drosophila functions to control the number of neuronal precursors in the peripheral nervous system. Development 116:31-40.

Reizer J, Reizer A, Saier MH (1993) The MIP family of integral membrane channel proteins: sequence comparisons, evolutionary relationships, reconstructed pathway of evolution, and proposed functional differentiation of the two repeated halves of the proteins. Crit Rev Biochem Mol Biol 28:235-257.

Rickles RJ, Botfield MC, Weng Z, Taylor JA, Green OM, Brugge JS, Zoller MJ (1994) Identification of Src, Fyn, Lyn, PI3K, and Abl SH3 domain ligands using phage display libraries. EMBO J 13:5598-5604.

Rivers RL, Dean RM, Chandy G, Hall JE, Roberts DM, Zeidel ML (1997) Functional analysis of nodulin 26, an aquaporin in soybean root nodule symbiosomes. J Biol Chem 272:16256-16261.

Sato K, Aoto M, Mori K, Akasofu S, Tokmakov AA, Sahara S, Fukami Y (1996) Purification and characterization of a src-related p57 protein-tyrosine kinase from Xenopus oocytes. J Biol Chem 271:13250 13257.

Sato K, Iwasaki T, Tamaki I, Aoto M, Tokmakov AA, Fukami Y (1998) Involvement of protein-tyrosine phosphorylation and dephosphorylation in sperm-induced Xenopus egg activation. FEBS Lett 424:113-118.

Sato K, Iwao Y, Fujimura T, Tamaki I, Ogawa K, Iwasaki T, Tokmakov AA, Hatano O, Fukami Y (1999) Evidence for the involvement of a src-related tyrosine kinase in Xenopus egg activation. Dev Biol 209:308-320.

Savchenko A, Kraft TW, Molokanova E, Kramer RH (2001) Growth factors regulate phototransduction in retinal rods by modulating cyclic nucleotide-gated channels through dephosphorylation of a specific tyrosine residue. Proc Natl Acad Sci USA 98:5880-5885.

Scavo L, Shuldiner AR, Serrano J, Dashner R, Roth J, De Pablo F (1991) Genes encoding receptors for insulin and insulin-like growth factor I are expressed in Xenopus oocytes and embryos. Proc Natl Acad Sci USA 88:6214-6218.

Skeath JB (1998) The Drosophila EGF receptor controls the formation and specification of neuroblasts along the dorso-ventral axis of the Drosophila embryo. Development 125:3301-3312.

Songyang, Z, Carraway III KL, Eck MJ, Harrison SC, Feldman RA, Mohammadl M, Schlessinger J, Hubbard SR, Smith DP, Eng C, Lorenzo MJ, Ponder BAJ, Mayer BJ, Cantley LC (1995) Catalytic specificity of protein-tyrosine kinases is critical for selective signalling. Nature 373:536-539.

Tsukaguchi H, Shayakul C, Berger UV, Mackenzie B, Devidas S, Guggino WB, van Hoek AN, Hediger MA (1998) Molecular characterization of a broad selectivity neutral solute channel. J Biol Chem 273:24737-24743

Udolph G, Urban J, Rüsing G, Lüer K, Technau GM (1998) Differential effects of EGF receptor signalling on neuroblast lineages along the dorsoventral axis of the Drosophila CNS. Development 125:3291-3299.

Volk KA, Husted RF, Snyder PM, Stokes JB (2000) Kinase regulation of $\mathrm{hENaC}$ mediated through a region in the $\mathrm{COOH}$-terminal portion of the $\alpha$-subunit. Am J Physiol 278:C1047-C1054.

Wangh LJ (1989) Injection of Xenopus eggs before activation, achieved by control of extracellular factors, improves plasmid DNA replication after activation. J Cell Sci 93:1-8

Weaver CD, Shomer NH, Louis CF, Roberts DM (1994) Nodulin 26, a nodule-specific symbiosome membrane protein from soybean, is an ion channel. J Biol Chem 269:17858-17862.

Wischmeyer E, Doring F, Karschin A (1998) Acute suppression of inwardly rectifying Kir2.1 channels by direct tyrosine kinase phosphorylation. J Biol Chem 273:34063-34068.

Wolf DP (1974) The cortical response in Xenopus laevis ova. Dev Biol 40:102-115.

Yasui M, Hazama A, Kwon T-H, Nielsen S, Guggino WB, Agre P (1999) Rapid gating and anion permeability of an intracellular aquaporin Nature 402:184-187.

Yool AJ, Stamer WD, Regan JW (1996) Forskolin stimulation of water and cation permeability in Aquaporin 1 water channels. Science 273 1216-1218. 